\title{
Interactions between real economic and financial sides of the US economy in a regime-switching environment
}

\author{
Soodabeh Sarafrazi ${ }^{\mathrm{a}}$, Shawkat Hammoudeh ${ }^{\mathrm{a}, \mathrm{b}, *}$ and Mehmet Balcilar ${ }^{\mathrm{b}, \mathrm{c}, \mathrm{d}}$
}

\author{
${ }^{\mathrm{a}}$ Lebow College of Business, Drexel University, Philadelphia, PA, USA ${ }^{\mathrm{b}}$ IPAD Lab, IPAG Business School, \\ Paris, France \\ ${ }^{\mathrm{c}}$ Department of Economics, Eastern Mediterranean University, Famagusta, Turkey \\ ${ }^{\mathrm{d}}$ Department of Economics, University of Pretoria, Pretoria, South Africa
}

${ }^{\star}$ Corresponding author. E-mail: Shawkat.hammoudeh@drexel.edu

This objective of this study is to examine the linkages between real (economic) and financial variables in the United States in a regime-switching environment that accounts explicitly for high volatility in the stock market and high stress in financial markets. Since the linearity test shows that the linear model should be rejected, we employ the Markov-switching VECM to examine the same objective using the Bayesian Markov-chain Monte Carlo method. The regime-dependent impulse response function (RDIRF) highlights the increasing importance of the financial sector of the economy during stress periods. The responses and their fluctuations are significantly greater in the high-volatility regime than in the low-volatility regime.

Keywords: real and financial sectors; Bayesian MCMC method; regime-dependent impulse; VIX; FSI

JEL Classification: E10

\section{Introduction}

The sub-prime mortgage crisis that took place in the United States in summer 2008 had spread to other financial markets and morphed into a global financial crisis. It had contributed to the Great Recession that took place in 2007-2008 which was caused by problems in capital and real estate markets and led to lower economic growth worldwide. This crisis has rekindled interest in the migration, transmission and volatility of financial risks and their impacts on real economic activity. Since it has caused structural breaks in many economic and financial series, the relationships between the financial and economic variables are likely to be nonlinear, which should be accounted for in the empirical analysis this study 
focuses on. Thus, a single-state framework is unrealistic to analyse the real and financial sides of the US economy, given that the states of the economy are dynamic rather than static and the gravity of the events that are embedded in the sample period. The Markov-switching approach is a popular technique in dealing with nonlinearity and structural breaks because it allows both the coefficients and variances to change based on the prevailing regime. It also allows for the estimation of the impulse-response functions (IRFs) and their confidence intervals based on the Markov-chain Monte Carlo method (MCMC) of Gibbs sampling.

Policymakers consider wealth as an important driver of the economy and view stock markets and oil prices as important predictors of the business cycle. For example, researchers have long considered the stock market in the US as an important predictor of the business cycle (Moore, 1983; Siegel, 1991; Chauvet, 1998/1999). Siegel (1991) determines that out of the 41 recessions observed since 1802, 38 were preceded by at least an $8 \%$ loss in stock market returns. Other researchers acknowledge the predictive ability of crude oil prices. Hamilton $(2003,2009)$ argues that oil price shocks proximately cause the post-WWII recessions in the US.

Following the Great Recession, there is also growing interest in the impact of financial and uncertainty, which arises from risk, fear and volatility in financial markets, on the real economic activity. Although there are several studies examining the links between the financial markets and the real sector (Moore, 1983; Chen et al., 1986; Siegel, 1991; Chauvet, 1998/1999; Andreopoulos, 2009; Aboura and van Roye, 2013; Semmler and Chen, 2014) and the oil price and its impact on real output (Hamilton, 2003, 2009; Kilian, 2008); to our knowledge, no study has examined the joint interactions of the real economic activity, financial uncertainty and oil price, taking into account the recent global financial crisis and the Greater Recession. The three groups of variables may all interact and their joint dynamics may reveal significant information pertinent to the transmission mechanisms of risks and shocks from the sectors under consideration. Our study is novel in its examinations of joint dynamics of the real economic activity, financial risk variables and the oil price where nonlinearity in the form of regime-switching explicitly models the joint and complex dynamics among these variables. Differently from other studies, we in this study explicitly recognize the investment impact by including the US real capital stock, labour force, industrial production (IP) and real interest rates in the model.

The broad goal of this study is to estimate a theoretically sound empirical model that examines the interactions between real economic and financial variables, while accounting for the effects of stress and volatility in the transmission dynamics of the variables. This is achieved through examining the following six objectives. The first objective is to check the nonlinearity of the dynamic system that contains the real economic variables including the real capital stock, employment and real oil prices, as well as the financial variable which is the long-term interest rates. The presence of nonlinearity is examined by exploring the presence of regime switching. The second objective is to explore the interrelations between the financial risks and economic activity in the presence of financial stress and stock market volatility, using the regime-dependent impulse responses. The third objective is to analyse whether these relationships, if they exist, are sensitive to changes in the underlying volatility regimes, given the exogenous financial risk and stress indicators. The fourth is to investigate which measure of the financial risk and stress variables (VIX, financial stress index (FSI) and US Economic uncertainty index $)^{1}$ has the strongest impact on these variables and, therefore, can be used more effectively to discern the financial impact on the future economy. The fifth objective is to determine the ways in which the variables respond to shocks in both the calm and turbulent periods by performing the impulse response analysis. The sixth and final objective is to investigate the forces that affect the transmission of the underlying volatility regimes.

This article makes contributions to the literature in two ways. First, it provides a framework that quantifies the relationship between financial and economic variables. Second, it applies advanced methods that better capture the complex dynamics among the variables. In particular, the Bayesian MCMC-based IRFs, which allows one to obtain the confidence intervals for the IRF of the MS-VECM, are used to examine the extent of the responses of shocks to the

\footnotetext{
${ }^{1}$ We have initially estimated models with policy uncertainty indexes. However, we were not able to find any significant impact from policy uncertainty index to other variables.
} 
real and financial variables under the two regimes. Computing multistep IRFs from MS-VECM as well as from all nonlinear time-series models prove complicated because no ordinary method of computing the future paths of the regime process exists. The MCMC-based impulse robustly incorporates those future paths and allows propagation of the shocks in a regime-dependent manner.

The empirical model that examines the interactions between the real economic and financial risk variables, while accounting for the effect of the US financial stress and the stock market volatility, will have the following relationships. First, the production function for output growth as represented by changes in real IP is stipulated to depend on changes in capital stock, employment, oil prices, financial variables, financial stress and stock market volatility. Second, the endogenous financial variable, the real long-term interest rate, depends on both the real economic and exogenous financial variables. Those exogenous financial variables include the CBOE volatility index known as VIX and the Federal Reserve Bank of St. Louis' FSI.

In this way, we can investigate the directional transmission of risks between real economic and financial variables. We can also explore the impacts of shocks in the capital markets' volatility and financial stress on these real and financial variables. The findings show the system follows two regimes where regime 1 (the low volatility or noncrisis regime) has more than 3.5 duration time than regime 2 (the high volatility or recession/crash regime). The high-volatility regime corresponds almost $100 \%$ of the time to the recession periods documented by the National Bureau of Economic Research (NBER), and thus can be dubbed the recession regime. There are more interrelations between the real and financial variables in the low- than the high-volatility regime. ${ }^{2}$ The financial variable responds faster to shocks than the oil and economic activity variables, but its response is less asymmetric across the regimes, compared to the response of the real economic activity and oil variables. The responses of the real activity and oil variables are highly asymmetric and have a regimedependent magnitude, speed and shape. The impacts of stock market volatility and financial markets stress go first through the financial variables and the oil price before they reach the economic activity variables. The per capita capital stock does not respond to stock market volatility and financial stress in the low-volatility (noncrisis) regime, while it responds with delay only in the high-volatility (recession/crash) regime.

The remainder of the article is organized as follows. Section II provides a brief review of the related literature. Section III presents the data description. Section IV describes the linear and nonlinear models. Section V discusses the results, and Section VI concludes the article.

\section{Literature Review}

Most of the recent literature that deals with financial and economic issues uses the linear VAR model and VECM. These first-generation models do not capture the nonlinear relationships among the variables, which have become more common because of reoccurrences of crises, structural breaks and differential effects of booms and busts. We test for nonlinearity and use nonlinear models with a focus on regimeswitching to capture spillovers between financial and real variables in an environment that includes economic uncertainty and financial stress, in addition to frequent switches between turmoil (recession/crash) and tranquility (noncrisis) regimes in our designation.

A growing literature emphasizes the role of fluctuations in financial markets in driving financial and business cycle dynamics (e.g. Bernanke and Gertler, 1999). With the onset of the Great Recession, it has become increasingly clear that financial variables constitute an important class of leading indicators for the real economy. First, asset-price variations potentially affect the real economy as a consequence of a direct effect on household wealth on consumption demand (e.g. Zhou and Carroll, 2012; Case et al., 2013; Guerrieri and Iacoviello, 2013; Liu et al., 2013; Mian et al. 2013). Second, the balance-sheet channel argues that credit markets include significant frictions, whereby borrowers with strong financial credentials stand a better chance of obtaining a loan than borrowers with weak financial credentials. Forward-looking asset prices may provide useful information about the pace of

\footnotetext{
${ }^{2}$ This is evident by higher impulse responses in the high-volatility regime, as compared to the response in the low
} (noncrisis) volatility regime. 
future economic activity, specifically future changes in output and/or inflation (Forni et al., 2003; Stock and Watson, 2003; Gupta and Hartley, 2013). Despite the evidence of this leading indicator property, the causal relationships between output and asset prices appear to be complicated and empirically difficult to identify (International Monetary Fund (IMF), 2000). One strand of the literature emphasizes that asset prices influence current expenditure solely to the extent that they are 'leading indicators' of the future variations in economic activity. Additionally, forward-looking, rational economic agents incorporate the fluctuations in financial asset prices in their expectations (Gelain and Lansing, 2013), which in turn affects the propagation mechanism of shocks. The emergence of asset-price inflations caused a reappraisal of what monetary policy makers should or should not do when faced with rapid increases in asset prices. Bernanke and Gertler (1999) argue that policymakers do not need to respond to rising asset prices that reflect changing fundamentals in asset markets.

The existing literature pays more attention to the relationships between financial fundamentals and oil prices than to the relationships between financial risks and real economic activity variables, which will be discussed in this article. This review of the literature focuses on studies that use linear and nonlinear models to examine the relationship between financial fundamentals, IP, oil prices, VIX, economic uncertainty and financial stress.

\section{Financial risks}

This strand of the literature explores the transmission of financial risks among different financial markets. Fernandes et al. (2009) examine the time-series properties of the daily equity VIX and S\&P 500 stock returns. These authors suggest that VIX display a long-range dependence, and thus violate the weak efficiency hypothesis. They also find evidence of a strong relationship between the VIX and the S\&P 500 index return. They further show that the equity VIX is negatively related to the long-run oil price, suggesting that the equity market risk declines as demand for oil strengthens as the economy gains strength. ${ }^{3}$

Figuerola-Ferretti and Paraskevopoulos (2010) consider cointegration and the price discovery process between two types of credit risk, as represented by credit default swap (CDS) spreads, and market risk as measured by the equity VIX. The authors find that the CDS and VIX are cointegrated and that VIX leads the CDS market in the price discovery process. Bekaert et al. (2012) decompose VIX into two components: the risk aversion and the expected stock market volatility. The authors develop the risk analysis further by investigating the dynamic links between those two risk components and the monetary policy. Their results show that only the risk-aversion component responds to the lax monetary policy. However, the increasing expected stock market volatility contributes to a laxer monetary policy.

Gogineni (2010) investigates the impact of changes in the daily oil price on the equity return of a wide group of industries. The author shows that stock returns of both industries that depend heavily on oil and those that use little oil but their customers use oil products are sensitive to changes in oil price. Çatik and Önder (2011) estimate oil price-augmented Phillips curves with linear and Markov regime-switching models and find that these MS models show an asymmetric structure of oil pass-through and indicate the existence of two different regimes characterized as the high- and the low-inflation periods.

\section{Markov-switching modelling}

As stated above, the linear VAR model/VECM which focus on one regime have been the popular approach in examining causal relationships between the variables under consideration. But most financial and economic series exhibit nonlinear behaviour because of recurrence of structural breaks, and thus are subjected to some form of regime switching.

One of the challenges facing empirical models has been the incorporation of structural breaks into the models endogenously. Bai and Perron (1998, 2003) develop procedures for detecting and dating multiple structural breaks in time series. These procedures have been used extensively in the

${ }^{3}$ For the emerging markets, the literature also documents significant interactions between the oil price, economic activity and asset markets. Nikkinen et al. (2014) and Lin et al. (2014) examine the oil price shocks and asset markets, while Fernandez (2014) investigates the impact of macroeconomic factors on financial markets. 
literature and the general conclusion points to frequent existence of multiple structural breaks in economic time series. For example, Kim and Nelson (1999), McConnell and Pérez-Quirós (2000), Blanchard and Simon (2001), and Ahmed et al. (2004), among others, document structural changes in the volatility of US GDP growth, finding a rather dramatic reduction in GDP volatility. Stock and Watson (2003), Bhar and Hamori (2003), Mills and Wang (2003), and Summers (2005) show structural breaks are associated with the decline in volatility of the output growth rates for Japan and other G7 countries, although the breaks also occur at different times. Further details and a review of the literature can be found in Hansen (2001) and Perron (2006). Markov-switching models are a class of models that can endogenously generate structural breaks and these models have been successfully used in the literature.

Andreopoulos (2009) uses the Markov-switching approach to estimate a nonlinear model for the real oil price, the real interest rate and the unemployment in the United States. His results indicate that the real interest rate matters during expansion for equilibrium unemployment. On the author hand, the author finds evidence that the real oil price has asymmetric effects on unemployment over the business cycle, particularly during recessions only, while is not being a regular feature of the US business cycle. Still, the oil price and not the real interest rate is significant for unemployment in the long run.

There is a growing research interest in financial risks under regime switching. Alexander and Kaeck (2008) find that within a Markov-switching model that the iTraxx Europe displays pronounced regimespecific behaviour. The determinants of the iTraxx are extremely sensitive to stock market volatility during periods of CDS spreads turbulence. However, these spreads are more sensitive to stock returns than to stock volatility during periods of ordinary market circumstances. Dionne et al. (2011) assess the ability of observed macroeconomic factors and the possibility of changes in regimes to explain the proportion in yield spreads caused by CDSs in a reduced form model. They have sought to measure the ability of observed macroeconomic variables and switching in regimes to explain the proportion of corporate bonds' yield caused by CDS spreads. The model is calibrated out of sample with consumption, inflation, risk-free yields and default data for different investment-grade bonds. The results show that inflation is a key factor for explaining default spreads. They also find that the estimated default spreads can explain up to half of the 10-year to maturity Baa zero-coupon yield in certain regime with different sensitivities to consumption and inflation through time. The results also indicate that the proportion of default spreads in yield spreads explained by aggregate consumption growth and inflation varies across the different regimes. This proportion is the greatest during the states of low volatility of consumption growth and high and volatile inflation.

Bollerslev et al. (2009) propose a method for constructing a volatility risk premium, or investor risk aversion, index. They implement the procedure with actual S\&P 500 option-implied volatilities (VIX) and high-frequency-based realized volatilities. They estimate the stochastic volatility risk premium for the US equity market and also link the variations in the risk premium to macro-finance state variables. They extract the volatility risk premium based on the difference between the implied volatility (VIX) and the realized volatility, which is the summation of intra-day high-frequency squared returns. They conclude that because the VIX index is calculated through a modelfree approach it acts as a better measure of the ex ante risk-neutral expectations of integrated volatility than the traditional Black-Scholes implied volatilities.

Giot (2003) applies the Markov-switching model to the S\&P 100 VIX and the German DAX VDAX indices and finds that these indices switch from a low-value state to a high-value state close to the events of the 1997 Asian crisis and have stayed almost continuously in the high-value state for the next five years. In the second part of the article, the author highlights the structural change in the asymmetric stock index volatility versus the (positive and negative) returns relationship and finds that the leverage effect is much weaker after the summer of 1997 than before. The reaction of volatility to negative market returns rises much faster in the low-volatility state than in the high-volatility state. Ardia (2003), inspired by the stylized facts (e.g. leverage effect, clustering and mean-reverting behaviour) of the S\&P 500 index and VIX, suggests a trading strategy that uses abnormally high volatility as a trading signal for long traders.

The more recent literature investigates whether the transition probabilities are constant and exogenous. 
Including the proper information variables in the transition probability function is crucial for the appropriateness of the time-varying transition probability (TVTP-MS) model and for the strength of the regimes identified by the model. Using a TVTP-MS model, Çevik et al. (2012) investigate the factors that affect the regime-switching probabilities of the US stock market in calm and turbulent periods. They consider manufacturing and nonmanufacturing business activity indices of the US Institute for Supply Management (ISM). They find that while the nonmanufacturing index only matters in bull periods the ISM manufacturing business activity index impacts the transition probabilities in both bull and bear regimes. Using four measures of oil price, the percentage change of oil price, the oil price increase, the net oil price increase and the scaled oil price increase, Chen (2010) finds that higher oil prices lead to a higher probability of the stock markets switching from the bull market to the bear market, as well as staying in the bear regime.

Semmler and Chen (2014) introduce a macro model with a finance-macro link which uses multiperiod decisions framework of economic agents. They use a multiregime VAR to study the impact of financial stress shocks on the macroeconomy in a large number of countries. By studying two regimes of financial stress, they find that in a regime of high financial stress, stress shocks can have large and persistent impacts on the real side of the economy, whereas in regimes of low stress, shocks can easily dissipate having no lasting effects. Aboura and van Roye (2013) develop an FSI for France by taking 17 financial variables that can be used as a real-time composite indicator for the state of financial stability in that country. Using a Markovswitching Bayesian VAR model, they show that an episode of high financial stress is associated with significantly lower economic activity, whereas movements in the index in a low-stress regime do not incur significant changes in economic activity.

Liu (2013) examines the dynamic relationships among different measures of financial risks including expected volatilities in the stock and Treasury bond markets and the gauge of financial stress on a monthly basis. Using a Markov-switching constant transition probability model, the author finds a significant relationship between the financial risks and the economic activity as represented by the IP. He also finds that the Merrill Lynch option volatility estimate (MOVE) and not VIX impacts IP in the conventional (linear) VECM.

\section{Data Description}

As indicated before, this study uses monthly data ${ }^{4}$ to examine the interrelationships between economic activity and financial variables in an environment that accounts for economic uncertainty and financial stress since most economic variables are available in monthly frequency. The real economic activity variables are represented by the real industrial production per capita (IPL), the real private capital stock per capita (KL) and the oil price (OIL). The financial variables include the real 10-year Treasury note rate (RIR), the Federal Reserve Bank of St. Louis's FSI and the S\&P 500 volatility index (VIX). As it will be explained in the unit root tests, the capital stock is integrated of degree two, $I(2)$, and thus we have to use capital stock per capita and industrial production per capita which are integrated of degree one. The monthly sample period ranges from December 1993 to October. $2013 .^{5}$

Table 1 summarizes the notation and sources of the data used in this study. The real private capital stock $(K)$ is sourced from Haver Analytics and then was converted from the quarterly to the monthly frequency, using autoregressive integrated moving average based on the Litterman (1983) method. ${ }^{6}$ Employment $(L)$ is the total nonfarm payroll and is obtained from the database of the Federal Reserve Bank of St. Louis. It measures the number of US workers in the economy

\footnotetext{
${ }^{4}$ Due to data availability, monthly data are preferred in this study. Financial data may have different dynamics in higher frequencies and this are usually about volatility dynamics which is captured by many moments greater than one. This study focuses on the short-run and long-run interactions of the levels (conditional means or the first moment) of the variables and different (ultra) high moment dynamics should affect our results. Moreover, interactions in the first moments also imply interactions in higher moments, but is not necessarily vice versa.

${ }^{5}$ Our sample period is restricted by the unavailability of St. Louis Fed Financial Stress Index (FSI) series before December. 1993.

${ }^{6}$ The Litterman's method allows nonstationary error processes and works for non-cointegrated series as well, while Chow and Lin (1971) allows only stationary error processes. We account for autocorrelation using an autoregressive process of order 1, AR(1).
} 
Table 1. Variable definitions and data sources

\begin{tabular}{|c|c|c|c|}
\hline Name & Description & Source & Exogenous/endogenous \\
\hline \multicolumn{4}{|c|}{ Real economic indicators } \\
\hline KL & Logarithm of real private capital stock per capita & Haver analytics & Endogenous \\
\hline IPL & $\begin{array}{l}\text { Logarithm of real industrial production per capita } \\
\text { (base year }=2007)\end{array}$ & Federal Reserve & Endogenous \\
\hline $\mathrm{L}$ & Total nonfarm employment & Federal Reserve & \\
\hline OII & Logarithm of monthly crude oil spot price (WTI) & Federal Reserve & Endogenous \\
\hline \multicolumn{4}{|c|}{ Financial indicators } \\
\hline FSI & Financial stress & $\begin{array}{l}\text { Federal Reserve Bank } \\
\text { of St. Louis }\end{array}$ & Exogenous \\
\hline RIR & Real interest Rate $=$ DSG10-inflation rate & $\begin{array}{l}\text { Federal Reserve Bank } \\
\text { of St. Louis }\end{array}$ & Endogenous \\
\hline VIX & $\begin{array}{l}\text { Chicago Board Options Exchange's market } \\
\text { volatility index on near-term volatility of S\&P } \\
500 \text { stock index }\end{array}$ & DataStream & Exogenous \\
\hline
\end{tabular}

Notes: Exogenous and endogenous refer how the variable enters into the linear VEC and Markov-switching VEC models. WTI, West Texas Intermediate.

who contribute to GDP. The OIL represents the WTI oil price and is sourced from the Energy Information Administration. RIR is the difference between the 10-year Treasury constant maturity rate and inflation rate. Both series are obtained from the St. Louis Fed's database. The FSI measures the degree of financial stress in the financial markets and is constructed from 18 financial series, where each of these series captures some aspect of financial stress. The equity VIX, which is sourced from DataStream, is an index that measures expectations of volatility of the S\&P 500 index over the next 30-day period. It is calculated based on the options on the S\&P 500 equity index and quoted in percentage points. ${ }^{7}$ It is referred to as the 'fear index' in the equity market. An increase in VIX is usually associated with a decrease in the S\&P 500 index. The VIX usually spikes as stocks go down to capture anxiety in the stock markets.

Figure 1 displays the plots of the time series used in the empirical analysis. The industrial production per capita shown in Fig. 1, which is also released by the St. Louis Fed, is an index that measures the real production output in the US, having 2007 as the base year. As can be seen in Fig. 1, the real capital stock per capita is steady during the years 1994-2000 because both the capital stock and employment increased in those years. Then it started to move up until it peaked in 2009 as the employment dropped, while the capital stock continued to rise. Its unusual behaviour during the last few years reflects a drop in employment more than a change in the capital stock, which basically levels off in those years. The IPL has generally an upward trend during the sample period. However, it has two major bumps: the first one is in 2000-2002, which corresponds to the dotcom technology bubble recession, and the second is in 2007-2008, which coincides with the Great Recession period. It should be noted that this variable has these drops despite the decrease in employment, which signifies considerable decline in IP itself. The real WTI price does not change much during the years 1994-2002. Then this price increases sharply until it peaked in 2008. It plunges during the Great Recession of 20072008 , and then recovers after the recession ended but still stayed below its peak in 2008. The real long-run interest rate is highly volatile over the sample period but generally has a decreasing trend despite the muted steadiness of inflation. The VIX index stays steady during the sample period except during the Great Recession when it jumps up considerably, reflecting the heightened fear during those years. It also jumps at the end of 2010 and 2011. The FSI shows a behaviour somewhat similar to that of VIX.

\footnotetext{
${ }^{7}$ For example, if VIX is 50 , one can infer that the index options markets expect with a $68 \%$ probability the S\&P 500 index to move up or down $\frac{50 \%}{\sqrt{12 \text { months }}} \approx 14 \%$ over the next 30 -day period.
} 


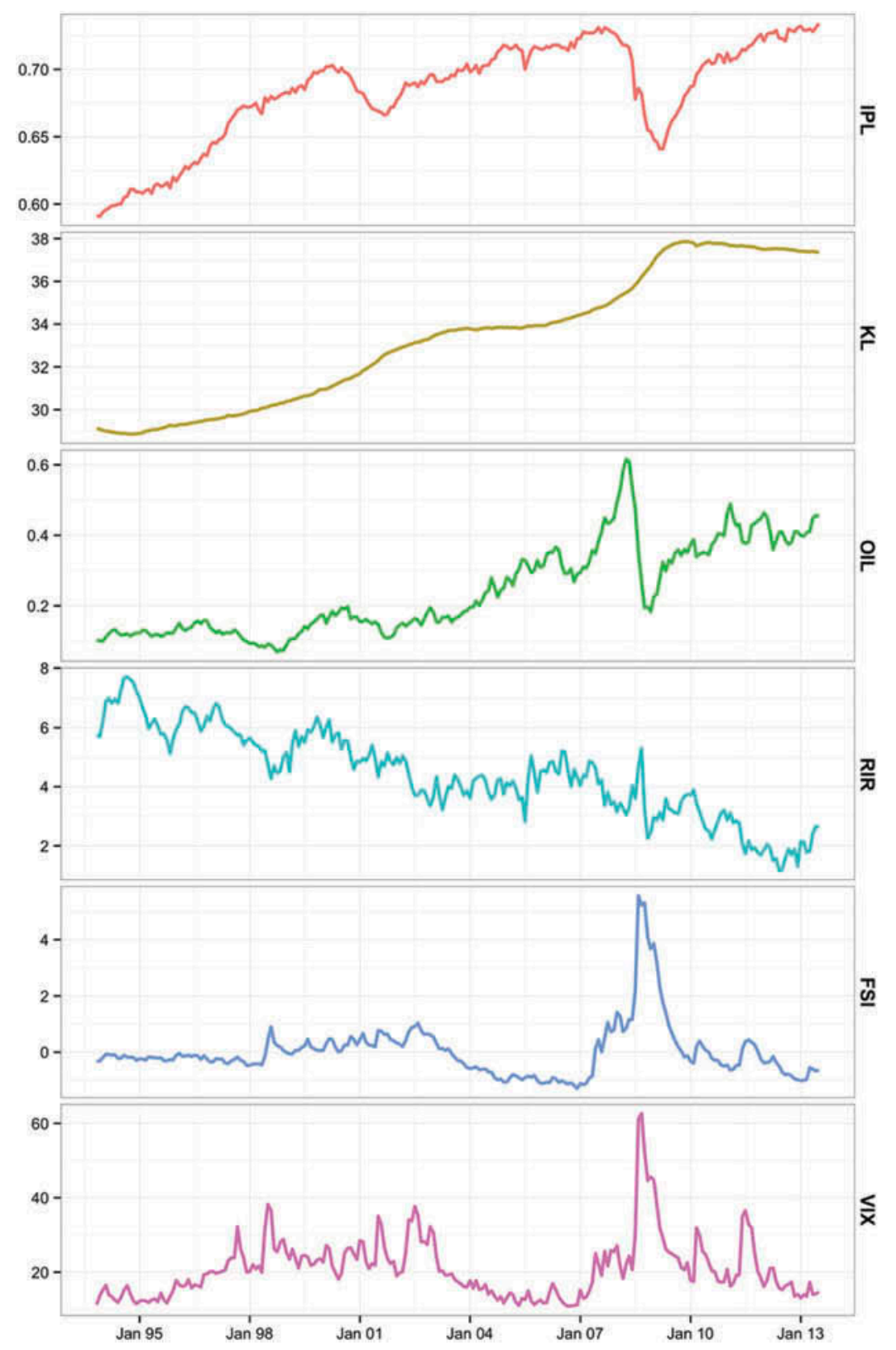

Fig. 1. The economic activity and financial risk variables

Notes: the figure plots levels of the monthly series. KL, real private capital stock per capita; IPL, real industrial production per capita; OIL, oil price; RIR, real 10-year treasury note rate; VIX, the S\&P 500 volatility index; FSI, Federal Reserve Bank of St. Louis financial stress index. The IPL series is scaled by $10^{-6}$ for easy labelling of the axis. The sample period covers December 1993 to October 2013 with 238 observations.

Regarding the descriptive statistics displayed in Table 2, the oil price has the highest growth on average, while industrial production per capita has the lowest, among the economic variables. The average monthly growth rates over the sample period are $0.092 \%, 0.105 \%$ and $0.642 \%$ for the industrial production per capita, capital stock per capita and the oil price, respectively. The growth for the capital stock per capita thus comes right before that of the industrial production per capita. On the other hand, the percentage change in real long-run interest rate is negative with an average monthly percentage change of $-0.316 \%$. In terms of volatility as represented by $\mathrm{SD}$, the monthly volatility figures for the first growth rates of industrial production per capita, capital stock per capita, oil price and the real long-run interest rate 
Table 2. Descriptive statistics

\begin{tabular}{|c|c|c|c|c|c|c|}
\hline \multirow[b]{2}{*}{ Variable } & \multicolumn{3}{|c|}{ Real economic indicators } & \multicolumn{3}{|c|}{ Financial indicators } \\
\hline & $\triangle I P L$ & $\Delta K L$ & $\Delta O I L$ & $\Delta R I R$ & VIX & FSI \\
\hline Mean & 0.000920 & 0.001052 & 0.006419 & -0.003163 & 20.84702 & 0.014932 \\
\hline Median & 0.001100 & 0.000935 & 0.014685 & -0.007834 & 19.68750 & -0.170000 \\
\hline Maximum & 0.018212 & 0.006269 & 0.205494 & 0.500601 & 62.63947 & 5.565000 \\
\hline Minimum & -0.039669 & -0.003428 & -0.323713 & -0.491203 & 10.81762 & -1.289000 \\
\hline S.D & 0.006060 & 0.001470 & 0.079778 & 0.113142 & 8.184033 & 0.997722 \\
\hline Skewness & -1.620666 & 0.636963 & -0.737485 & 0.028350 & 1.803219 & 2.853865 \\
\hline Kurtosis & 12.05056 & 4.091191 & 4.736866 & 6.790446 & 8.320367 & 14.51918 \\
\hline JB & 912.6366 & 27.78416 & 51.27334 & 141.9106 & 407.9628 & 1632.039 \\
\hline$p$-Value (JB) & 0.000000 & 0.000001 & 0.000000 & 0.000000 & 0.000000 & 0.000000 \\
\hline
\end{tabular}

Notes: All variables except RIR and FSI are in first difference of natural logarithm. The sample period is from December 1993 to October 2013 with 238 observations. The variables are as follows: KL, real private capital stock per capita; IPL, real industrial production per capita; OIL, oil price; RIR, real 10-year treasury note rate; VIX, S\&P 500 volatility index; FSI, Federal Reserve Bank of St. Louis financial stress index. $\Delta$ denotes first differencing. In addition to the mean, the SD, minimum, maximum, skewness and kurtosis statistics, the table reports the Jarque-Bera normality test (JB) and its $p$-value, denoted as $p$-value $(\mathrm{JB})$.

are $0.606 \%, 0.147 \%, 0.798 \%$ and $11.314 \%$, respectively. Thus, the real long-run interest rate is more volatile than the oil price, while both variables are much more volatile than the industrial production per capita and the capital stock per capita.

All the variables of interest except RIR have significant asymmetric distributions as revealed by the skewness statistics. The kurtosis statistics for FSI, VIX, $\Delta \mathrm{KL}, \Delta \mathrm{IPL}$ and $\Delta \mathrm{RIR}(\Delta \mathrm{KL}, \Delta \mathrm{IPL}$ and $\Delta \mathrm{RIR}$ are the first differences of the logarithms of private capital stock per capita, log of real industrial production per capita and real interest rate) are higher than 3, thereby implying that the extreme values for these variables may occur more frequently than would be predicted by the normal distribution, the well-known 'fat tails' phenomena. The Jarque-Bera statistics for all variables reject the null hypothesis of normal distribution at the $1 \%$ significance level.

We use the ADF and Phillips-Perron (PP) statistics to test for unit roots among the variables. The results of these tests for both the level and first difference are shown in Table 3. The existence of unit roots for IP and $\mathrm{L}$ in level cannot be rejected, while it is rejected for their first differences. This means that they are $I(1)$. On the other hand, the presence of unit roots for the private capital stock $(K)$ cannot be rejected in the first difference either, which means that $K$ is $I(2)$. This should justify why we are using per capita for capital stock and consistently for IP. Since we use a Markov- switching model, it is of interest to see whether the unit root findings stay valid when nonlinearity is allowed in the Markov-switching unit root tests, leading to nonlinear root tests. ${ }^{8}$ We use the Markovswitching ADF (MS-ADF) test of Hall et al. (1999) and Camacho (2011) to check the robustness of the unit roots. The MS-ADF is appropriate since we also use the Markov-switching model to capture the nonlinear dynamics among the series. The MS-ADF test results reported in Table 3 do all confirm the results obtained from the standard ADF and PP tests. Thus, the regime-switching (nonlinearity) do not account for the nonstationarity in the data we use.

The Johansen cointegration test requires that all endogenous variables be $I(1)$. For this purpose, we divide $K$ by $L$, and capital stock per capita is $I(1)$. For consistency, we divide IP by $L$ and get IPL which is also I(1). All tests also support the presence of unit roots in OIL, and thus we consider it to be $I(1)$. Thus, all endogenous variables of the model are $I(1)$. Finally, all tests reject the presence of unit roots in VIX and FSI, which means these exogenous variables are $I(0)$ or stationary.

\section{Empirical Models}

We employ linear and nonlinear models to investigate the linkages between the economic and financial variables in an environment of

\footnotetext{
${ }^{8}$ We thank an anonymous referee who suggested the robustness check for the unit root tests by allowing nonlinearity.
} 
Table 3. Linear and nonlinear unit root tests

\begin{tabular}{|c|c|c|c|c|c|}
\hline & \multicolumn{2}{|c|}{ Panel A: level } & \multirow[b]{2}{*}{ MS-ADF } & \multicolumn{2}{|c|}{ Panel B: first difference } \\
\hline & $\mathrm{ADF}$ & $\mathrm{PP}$ & & $\mathrm{ADF}$ & PP \\
\hline \multicolumn{6}{|c|}{ Real economic indicators } \\
\hline $\mathrm{K}$ & -2.4837 & 3.5697 & $3.77441[0.99]$ & -1.1631 & -1.8970 \\
\hline IP & -2.4727 & -2.0076 & $-4.82410[0.45]$ & $-3.5510 * *$ & $-13.658 * * *$ \\
\hline $\mathrm{L}$ & -2.0349 & -1.7050 & $-7.37683 *[0.08]$ & $-3.2250 *$ & $-5.5689 * * *$ \\
\hline KL & -2.3877 & -2.4583 & $-112.18551[0.29]$ & $-3.1395 * * *$ & $-5.3834 * * *$ \\
\hline IPL & -2.6931 & -2.2280 & $-3.05517[0.84]$ & $-4.3016^{* * *}$ & $-14.905 * * *$ \\
\hline OIL & -3.1160 & -3.0880 & $-15.99698[0.08]$ & $-11.574 * * *$ & $-11.574 * * *$ \\
\hline \multicolumn{6}{|c|}{ Financial indicators } \\
\hline FSI & $-3.1327 * *$ & $-2.9327 * *$ & $-10.93469 * *[0.02]$ & $-11.483 * * *$ & $-11.459 * * *$ \\
\hline RIR & -2.1468 & -2.4119 & $-6.65410[0.12]$ & $-13.563 * * *$ & $-13.698 * * *$ \\
\hline VIX & $-3.5613 * *$ & $-3.8650 * *$ & $-4.69937 * *[0.03]$ & $-12.193 * * *$ & $-13.611 * * *$ \\
\hline
\end{tabular}

Notes: Panel A reports unit root tests for the log levels of the series, except the RIR and FSI which are in levels. Panel B reports the unit root test for the first differences of the log series. ADF (Dickey and Fuller, 1979) test. PP, Phillips-Perron unit root test (Phillips and Perron, 1988). MS-ADF, nonlinear Markov-switching ADF unit root test of Hall et al. (1999) and Camacho (2011). For the ADF and MS-ADF unit root tests, the lag orders are selected by the AIC. The bandwidth for the PP tests are select using the modified Bayesian Information Criterion (BIC)-based data dependent method of $\mathrm{Ng}$ and Perron (2001). The numbers in brackets are bootstrap $p$-values of the MS-ADF test obtained with 2000 draws. $* * * * *$ and $*$ represent significance at the $1 \%, 5 \%$ and $10 \% 1$ levels, respectively.

economic and financial uncertainty. We test for linearity of the VECM, and if this specification is rejected, then we opt for using the nonlinear Markov regime-switching model because it can examine the interactions among the variables in both tranquil (no-crisis) and turmoil (recession/ crash) environments.

In order to estimate the models, we start with the Johansen cointegration analysis for the system that includes IPL, KL, RIR and OIL as the endogenous variable and VIX and FSI as exogenous. The system is based on an aggregate production function which depends on labour, capital stock and energy represented by the WTI oil price (Hamilton, 2003). This function is modified to include the effect of uncertainty in the financial sector which is represented by the measure of fear and volatility in the stock markets (VIX) and the financial stress variable (FSI), as explained earlier. The capital stock is based on cumulative investment which is a function of interest rate and the other variables in the system. Therefore, production decisions are based on a confluence of factors that reflect the interactions of the real and financial sectors in the economy. Then the production function in which output is represented by IP can be specified as

$$
I P_{t}=f\left(K_{t}, L_{t}, R I R_{t}, O I L_{t}, Z_{t}\right)
$$

where the variables in this function are defined as before except $Z_{t}$ which is assumed to be a vector of exogenous variables and represents financial stress and equity volatility. Given certain stylized facts about the capital stock as explained earlier, we have to express this function in per capita terms for the IP and the capital stock as

$$
I P L_{t}=f\left(K L_{t}, R I R_{t}, O I L_{t}, Z_{t}\right)
$$

After estimating the linear model, the linearity of this model will be statistically tested and the nonlinear Markov regime-switching (MS) method will also be employed. Using the Johansen $(1988,1991)$ maximum likelihood (ML) procedure to test for cointegration, Table 4 shows that this test suggests two vector error correction terms (ECTs). Finally, if the results warrant using the MS model, we follow Krolzig et al. (2002) by incorporating the cointegrating properties into the MS model. 
Table 4. Cointegration tests and estimates of the linear VECM

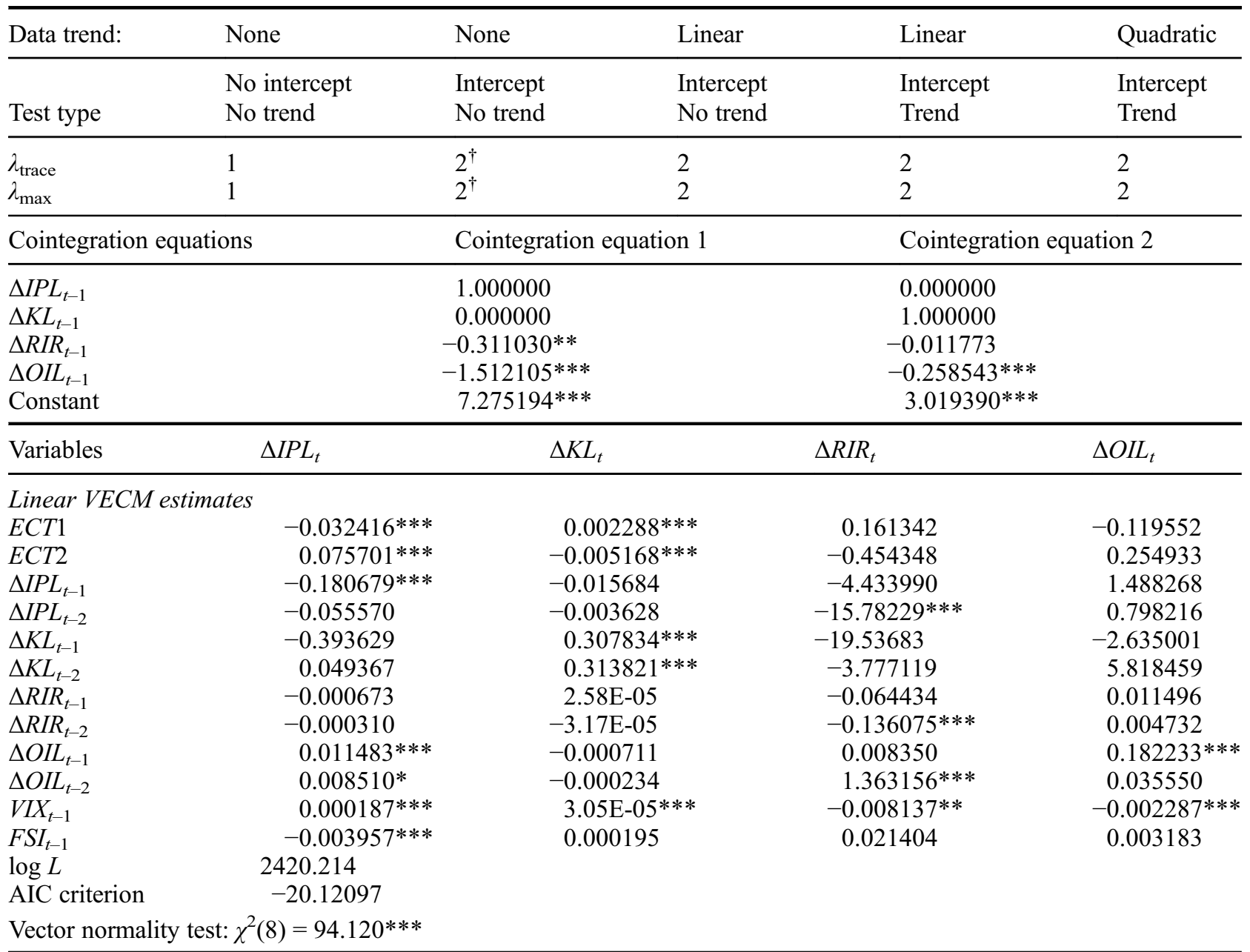

Notes: the table reports the maximal eigenvalue $\left(\lambda_{\max }\right)$ and trace $\left(\lambda_{\text {trace }}\right)$ cointegration order tests of Johansen (1988, 1991) under various trend specifications. ${ }^{\dagger}$ denotes the cointegration order and trend specification selected by the BIC. The normalized cointegration vectors for $r=2$ cointegration order are reported using recursive (triangular) identification. Vector normality test is calculated using the approach proposed in Doornik and Hansen (1994). The model is estimated over the full sample period December 1993 to October 2013, with 238 observations. $\Delta$ denotes first differencing. $* * *, * *$ and $*$ represent significance at the $1 \%, 5 \%$ and $10 \%$ levels, respectively.

\section{Linear VECM}

Let $X_{t}$ denote a $p$-dimensional column of the $I(1)$ variables, which follows a $\operatorname{VAR}(k)$ process:

$$
\begin{aligned}
X_{t}= & \mu+A_{1} X_{t-1}+A_{2} X_{t-2}+\ldots+A_{k} X_{t-k} \\
& +\varphi_{1} Z_{t-1}+\ldots+\varphi_{s} Z_{t-s}+\varepsilon_{t}
\end{aligned}
$$

where $\mu$ is the deterministic term, $k$ is the lag order and $\varepsilon_{t}$ is a Gaussian error term. ${ }^{9}$ Vector $X$ includes the endogenous variables IPL, KL, RIR and OIL which are expressed in natural logarithms, except the RIR

${ }^{9}$ A deterministic time trend can be included as well. which is in level. Vector $Z$ includes the exogenous variables VIX and FSI. The VAR $(k)$ process can be written in the following VECM representation:

$$
\Delta X_{t}=\mu+\sum_{i=1}^{k-1} \Gamma_{i} \Delta X_{t-i}+\Pi X_{t-1}+\sum_{j=1}^{s} \varphi_{j} Z_{t-j}+\varepsilon_{t}
$$

where $\varepsilon_{t}$ is $p$-vector of independently and normally distributed error terms with covariance matrix $\Sigma$, $\varepsilon_{t} \sim I N(0, \Sigma), \Pi$ and $\Gamma_{i}$ are $p \times p$ matrices of 
coefficients representing the long-run impacts and the short-run adjustments, respectively. The matrix $\Gamma_{i}$ indeed represents the interim multipliers. The hypothesis of cointegration states that the long-run impact matrix, $\Pi$, can be written as

$$
\Pi=\alpha \beta^{\prime}
$$

where $\alpha$ and $\beta$ are $p \times r$ matrices. The columns of matrix $\beta$ form the cointegrating vectors, while matrix $\alpha$ contains the loading factors which are the weights of the cointegrating vectors in the various equations.

We will apply the linear VECM to the monthly data to account for interrelations of the financial variables with the economic activity variables. We will also use both the AIC and the SchwartzBayesian Criterion (BIC) to determine the VAR and cointegration specifications and the lag lengths. However, if there is a conflict, we use the BIC following the literature. The lag length $s$ for the exogenous variables is also specified using the AIC and BIC jointly with the order $k$ of the VAR model.

\section{Tests for nonlinearity}

To investigate the linearity assumptions in the VECM, we will first carry out the multivariate Jarque-Bera residual normality test because if the distribution is not normal it implies the presence of frequent outliers which is one of the properties of a nonlinear model. This test compares the third and fourth moments of the residuals to those for the normal distribution. If the results reject the null hypothesis that the residuals follow the multivariate normal distribution, then they imply the likely presence of nonlinearity in the VECM possibly due to frequent structural breaks. This leads one to investigate the presence of regime dependence of the relationships between variables in a regime-switching VEC (MS-VEC) model.

Additionally, when a Markov-switching model is estimated, we apply the conventional likelihood ratio (LR) test and the Davies (1987) test to test the linear VECM against the alternative of a nonlinear MS-VECM. The conventional LR test suffers from the nuisance parameter problem, which means that when there are unidentified parameters under the null hypothesis the LR statistic does not have the standard asymptotic $\chi^{2}$ distribution. Therefore, we include the adjusted LR test, known as the Davies (1987) test, as a cure. The test is used to calculate the approximate upper bound for the significance level of the adjusted LR statistic. ${ }^{10}$

\section{Markov regime-switching VECM}

The linear VECM discussed above presumes that the long-term cointegration, the short- term adjustments and the impacts of exogenous variables are constant over time. However, this assumption may be questionable since the co-movements of relevant variables might be subjected to structural breaks or regime changes, particularly when the transmission of risks is under consideration.

The methodology we adopt is based on a VECM with time-varying parameters where, given our objectives, the parameter time-variation directly reflects regime-switching. In this approach, changes in the regimes are treated as random events governed by an exogenous Markov process, leading to the MSVECM. The state of the market is determined by a latent Markov process, with the probability of the latent state process taking a certain value based on the sample information. In this model, inferences about the regimes can be made on the basis of the estimated probability, which is the probability of each observation in the sample coming from a particular regime. The MS-VECM we use to analyse the time-varying dynamic relationships among the real economic activity, financial variables and oil is an extension of the class of autoregressive models studied in Hamilton (1990) and Krishnamurthy and Rydén (1998). It also allows for asymmetric (regime-dependent) inference for the impulse response analysis. The structure of the MS-VECM

${ }^{10}$ Let $T$ denote the LR statistic, $m$ the number of coefficients in the conditional mean that vanish under the null hypothesis and $q$ the number of transition probabilities that vanish under the null hypothesis, then the conventional LR test is: $P\left[\chi^{2}(m+q)>T\right]$. The approximate upper bound under the adjusted LR test is given by

$$
P\left[\chi^{2}(q)>\mathrm{T}\right]+2 \mathrm{~T}^{1 / 2} \exp \left\{\left(\frac{q}{2}-0.5\right) \log (T)-\frac{\mathrm{T}}{2}-\frac{q}{2} \log (2)-\log \left(\frac{q}{2}\right)\right\} .
$$

If the adjusted LR test statistic exceeds the approximate upper bound, then the null hypothesis of linear specification is rejected. 
is based on the model studied in Krolzig (1997, 1999). Examples of these models, among others, include Psaradakis et al. (2004), Krolzig et al. (2002) and Francis and Owyang (2003). Our estimation approach is based on the Bayesian MCMC integration method of the Gibbs sampling, which allows one to obtain the confidence intervals for the IRF of the MS-VECM.

In order to account for the regime-dependent effects in our VECM, we incorporate the Markovswitching methodology by allowing for the presence of regime-dependent ECTs, the dynamics of the stationary part and the impacts of exogenous variables. The model is piecewise linear in each state but nonlinear across regimes. To carry the cointegrating properties derived in the linear VECM to the regime-switching model, we follow the methodology in Krolzig, 1997, 2006). Krolzig et al. (2002) use a two-step approach for MS-VEC modelling. In the first step, cointegration is established and vector ECTs are estimated using the Johansen (1988, 1991) ML procedure. In the second step, ECTs enter nonlinearly to the MS-VECM. In this approach, the endogenous variables adjust nonlinearly (asymmetrically) to the equilibrium.

We aim to estimate the model with the unobservable discrete state variables $s_{t}$, which has two possible states $\left(s_{t}=1\right.$ or $\left.s_{t}=2\right),{ }^{11}$ given as

$$
\begin{aligned}
\Delta X_{t}= & \mu\left(s_{t}\right)+\sum_{i=1}^{k-1} \Gamma_{i}\left(s_{t}\right) \Delta X_{t-i} \\
& +\Pi\left(s_{t}\right) X_{t-1}+\sum_{j=1}^{s} \varphi_{j}\left(s_{t}\right) Z_{t-j}+\varepsilon_{t}
\end{aligned}
$$

where $\varepsilon_{t}$ is a $p$-vector of independently and normally distributed error terms with heteroscedastic covariance matrix $\Sigma\left(s_{t}\right), \varepsilon_{t} \sim I N\left(0, \Sigma\left(s_{t}\right)\right)$. The endogenous and exogenous variables in this model are defined as in the linear VECM provided in Equation 2. The intercepts, $\mu$, the coefficients of the short-run impacts, $\Gamma_{i}$, the coefficients of the dynamics of the stationary part, $\Pi$, the coefficients for exogenous variables, $\varphi_{j}$, and the variance-covariance matrix of the innovations, $\Sigma$, are all conditioned on the realization of the state variable $s_{t}$. We place a restriction on the coefficients of the dynamics of the stationary part $\Pi$, assuming that only the $\alpha$ component is state dependent, while the $\beta$ component is state-independent, i.e. $\Pi\left(s_{t}\right)=\alpha\left(s_{t}\right) \beta^{\prime} .^{12}$

While $\beta$ represents the coefficients of the equilibrium impact which is assumed to be unchanged over the entire sample period, and hence regime-independent, $\alpha\left(s_{t}\right)$ stands for the regime-dependent adjustment coefficient that controls how the endogenous variables respond to the disequilibria represented by the $r$-dimensional vector $\beta^{\prime} X_{t}$. As such, a key distinction of the MS-VECM in Equation 4 is that the speed at which the variables adjust to the equilibrium varies across regimes. For example, a shock in the oil price will have different impacts on the per capita IP, per capita capital stock and the financial variables, depending on whether the economy is in a low- or a high-volatility regime. In this model, due to the nonlinear dynamics of the equilibrium errors, ${ }^{13}$ denoted by $\epsilon_{t}=\beta^{\prime} X_{t}$, the strength with which the equilibrium errors are corrected (measured by the matrix $\alpha\left(s_{t}\right)$ ), the impacts of the exogenous financial variables $\left(\varphi_{j}\left(s_{t}\right)\right)$ and the short-run dynamics of the endogenous variables (measured by the matrices $\Gamma_{i}\left(s_{t}\right)$ ) are time-varying. In our specification, the switches in the matrix $\alpha\left(s_{t}\right)$ can be interpreted as differences across regimes at the rate the equilibrium relationships obtain.

In our particular application, the maintained hypothesis is that $q=2$, i.e. two states or regimes for each variable are sufficient to describe the dynamic interactions among the variables we examine. This is consistent with crisis-recovery (recession-expansion) cycles observed in many financial and macroeconomic time series. A large number of studies show that the two-regime MS model is rich enough to capture the regime-switching behaviour in financial and macroeconomic time series

\footnotetext{
${ }^{11}$ We conduct the LR ratio test and use the Akaike and Schwartz information criteria on the number of regimes. The evidence supports that the number of regimes is two and not three. This result is available upon request.

${ }^{12}$ Our specification assumes constant and regime-independent cointegration vectors, while allows for the presence of the regime-dependent adjustment to the equilibrium. This specification is consistent with the nonlinear adjustment to the equilibrium examined in Savit (1988).

${ }^{13}$ Although the equilibrium parameters (represented by matrix ) are state-independent, Camacho (2005) shows that the equilibrium errors follow an MS-VARM under the specification in Equation 4. Indeed, Equation 4 can be obtained from a model where the equilibrium errors follow an MS-VAR process. To our knowledge, there is no theoretical result that allows us to estimate the MS-VECM with a state-dependent $\beta$, i.e. $\beta\left(s_{t}\right)$.
} 
(e.g. Hamilton, 1989; Diebold et al., 1994; Durland and McCurdy, 1994; Filardo, 1994; Ghysels, 1994; Kim and Yoo, 1995; Filardo and Gordon, 1998).

The MS-VECM in Equation 4 has some appealing properties for analysing the dynamic interactions of the variables in the short run and also in terms of their responses to disequilibria. ${ }^{14}$ First, it allows one to classify regimes as depending on the parameter switches in the full sample and, therefore, it is possible to detect the changes in dynamic interactions among the variables. Second, this model allows for many possible changes in the dynamic interactions among the variables at unknown periods. Third, it is possible to make probabilistic inference about the dates at which a change in regime occurred. We will be able to evaluate the extent of whether a change in the regime has actually occurred and also identify the dates of the regime changes. Finally, this model also allows one to derive the regime-dependent IRFs (RDIRF) to summarize whether the impact of a shock in one variable on other variables varies with regimes.

To determine the state transition probabilities, we follow Hamilton (1994) and define the transition probability matrix as

$$
\begin{aligned}
P= & \left(\begin{array}{ll}
p_{11} & p_{12} \\
p_{21} & p_{22}
\end{array}\right), \text { with } \sum_{j=1}^{2} p_{i j}=1, \text { and } p_{i j} \geq 0 \\
& \text { for } i=1,2
\end{aligned}
$$

where the $p_{i j}$ element of the $i$ th row and $j$ th column of the above matrix describes the transition probability from state $i$ to state $j$. The expected duration of regime $i$ is defined as $E\left(s_{t}=i\right)=1 /\left(1-p_{i i}\right)$. A shorter expected duration is usually expected for the highvolatility state. In order to estimate the MS-VECM, we adopt a two-step procedure due to Krolzig, 1997), Saikkonen (1992), Saikkonen and Luukkonen (1997), Krolzig et al. (2002) and Saikkonen and Lütkepohl (2000). Since all variables in the MS-VECM are stationary, the estimators are asymptotically normally distributed and the usual statistical inference applies
(Saikkonen, 1992; Krolzig, 1997; Saikkonen and Luukkonen, 1997; Krolzig et al., 2002). First, the number of cointegrating relationships is determined using the Johansen $(1988,1991)$ procedure. The equilibrium errors $\epsilon_{t}=\beta^{\prime} X_{t}$ are obtained in this first step. Second, the MS-VECM is estimated using the $\epsilon_{t}$ determined in the first step. Saikkonen (1992) and Saikkonen and Luukkonen (1997) show that the Johansen procedure estimates the cointegrating vectors consistently even in the presence of regime-switching.

The log-likelihood function is given by the sum of the regime log-densities of the observations conditional on the history of the process:

$$
L\left(\theta \mid I_{t}\right)=\sum_{t=1}^{T} \ln f\left(x_{t} \mid I_{t-1} ; \theta\right)
$$

with

$$
\begin{array}{r}
f\left(x_{t} \mid I_{t-1} ; \theta\right)=f\left(x_{t}, s_{t}=1 \mid I_{t-1} ; \theta\right)+f\left(x_{t}, s_{t}=2 \mid I_{t-1} ; \theta\right) \\
=\sum_{\delta=1}^{2} f\left(x_{t} \mid s_{t}=\delta, I_{t-1} ; \theta\right) \operatorname{Prob}\left(s_{t}=\delta \mid I_{t-1} ; \theta\right)
\end{array}
$$

where $I_{t}$ is the information set available at time $t$ and $\theta$ is the vector of parameters to be estimated. The likelihood function is maximized to obtain the estimates of the parameters of the model. There are three commonly used methods used for estimating the parameters of the MS models which are the ML, the expectation maximization (EM) and the MCMC methods. First, the simplest method is ML, but this method is computationally demanding and may have a slow convergence. Second, the EM algorithm is more commonly used for estimation of the MS models. However, the drawbacks of this method include the slow convergence and the disability to yield the SEs directly. Third, the Bayesian MCMC estimation is based on the Gibbs sampling. It may not be possible to compute the full vector of likelihoods for each regime in each period with the ML and EM methods

\footnotetext{
${ }^{14}$ This study considers conditional mean interactions as its core objectives, but volatility transmission is not explicitly allowed as it is not part of this study's goals. Allowing for volatility transmission would extensively complicate the model structure and it would also be difficult to estimate due to the presence of a large number of parameters. In relation to the importance of volatility transmission, our methodology follows the Granger causality approach, the most commonly used concept of volatility spillover in which the influence of a past shock of one series is emphasized on the current volatility of the other. Guidolin and Timmermann (2008) report that finding evidence of classical (ARCH effect is rather weak when the levels are modelled in a multivariate MS model. The MS models with a regime-switching variance have heteroscedastic conditional variance and may be rich enough to eliminate the ARCH effects in the residuals. Moreover, $\mathrm{Cheung}$ and $\mathrm{Ng}$ (1996) argue that the presence of volatility transmission has an ignorable impact on the analysis based on mean effects. Therefore, the impact of ignoring volatility transmission should have only an ignorable impact on our results.
} 
in certain cases. To avoid this problem, the MCMC works only with one sample path for the regimes rather than a weighted average of sample paths over all regimes (for more information, see Balcilar et al., 2015). ${ }^{15}$ We perform the MCMC integration with 50 000 posterior draws with a 20000 burn-in draws. ${ }^{16}$

\section{Impulse response analysis for the MS-VECM}

We analyse the dynamic interactions between the real and financial variables using the IRF. Computing the multistep IRFs from nonlinear time-series models is complicated because no ordinary method of computing the future path of the regime process exists. The IRFs of the MSVECM should ideally integrate the regime history into the propagation period, which is not easily resolved. Two approaches arose in the literature as a solution to the history-dependence problem of the IRFs in the MS-VECM. For this article, we use the approach of Ehrmann et al. (2003) for RDIRF and combine it with the Bayesian MCMC integration (Balcilar et al., 2015).

Analogous to the Bayesian impulse responses for the linear VAR models, using the approach of $\mathrm{Ni}$ et al. (2007), we derive the posterior density of the RDIRFs from the Gibbs sampling. The simulations of the posteriors of the parameters jointly with the identification of the structural shocks via the Gibbs sampler directly yield the posterior densities of the RDIRFs. The confidence bands are obtained by the MCMC integration with a Gibbs sampling of 50000 posterior draws with a burn-in of $20000 .^{17}$

\section{Results}

We will present the empirical results for the two models specified in the methodology, which are the linear VECM and the Markov regime-switching model. We will also apply the linearity test to the estimated linear model and determine which model will be statistically rejected.

\section{Linear VECM}

The linear VECM has two cointegrating vectors among the four economic, financial and oil variables under consideration, which suggest that there are two common stochastic trends (Table 4). ${ }^{18}$ In both longrun cointegrating (equilibrium) relationships, the oil price (OIL) is a loading factor that drives the long-run adjustment of the real industrial production per capita (IPL) and the real capital per capita (KL) to the equilibrium. Moreover, the real long-run interest rate is also a loading factor in the first cointegrating vector. This is not surprising because interest rate is influenced by the Fed and is a linking variable between the real and financial sectors, while the oil price, which is influenced by OPEC's decisions, affects physical investment as a substitute for capital or as a fuel and the financial variables because of the financialization of the oil market.

In this linear VECM, both IPL and KL participate in the correction towards the long-run equilibrium, while RIR and OIL do not. In the short run, IPL is influenced by itself, the oil price and the two exogenous financial variables, FSI and VIX. This finding underlines the importance of financial shocks on real economic activity in the short run and also underscores the importance of the financial sector in the real economy. As in the case for IPL, the per capita capital KL also participates in the error-correction and convergence to the long-run equilibrium but at a much lower speed than IPL does. In the short run, KL is affected by itself and VIX only, which also implies less short-run adjustment than for IPL. Interestingly, KL is not significantly impacted by the oil price, which implies there is not much substitution between capital and others as a result of changes in the oil price. This may be explained by not having too high oil prices on average to force factor substitution. In contrast to the two real economic variables, both RIR and OIL are not correcting to the equilibrium in the long run in this linear model,

\footnotetext{
${ }^{15}$ We modify the MCMC method of Balcilar et al. (2015) and introduce a rejection sampling scheme where the draws that violate the restriction that second regime has greater variance than the first regime for all equations are rejected.

${ }^{16}$ The details of the MCMC implementation is omitted to save space. We refer the interested reader to Balcilar et al. (2015) as our implementation is analogues to the MCMC procedure used there.

${ }^{17}$ Further details can be found in Balcilar et al. (2015).

${ }^{18}$ The BIC selects a restricted constant trend specification where a constant enters into the cointegration relationship. Both trace and maximal eigenvalue tests of Johansen $(1988,1991)$ indicate two cointegration vectors under the restricted constant specification.
} 
indicating that these variables behave weakly exogenously. In the short run, the real interest rate responds to changes in itself, IPL, OIL and VIX. This also shows that real economic variables can affect financial variables in the short run due to changes in production and oil prices.

Table 4 also reports the multivariate normality test, calculated as in Doornik and Hansen (1994). The normality of the residuals is strongly rejected by the multivariate normality test, indicating a possible presence of nonlinear dynamics in the system of variables. We also apply the adjusted LR test to test the linearity versus nonlinear regime-switching specifications (see Table 5). The adjusted LR statistic is considerably above the upper bound derived from the procedure in Davies (1987). Therefore, the linear specification of the VECM should be rejected.

\section{Markov regime-switching VECM}

The results of the linear VECM without any regime structure may simply capture the average effect or the normal state of the economy, thereby this model is rejected by the linearity test. Within the MS-VECM, we may likely find the parameter of a particular variable to be significant in one regime while is not in another regime, or it may even reverse its sign across regimes. The dynamic interactions among the variables as captured by the impulses responses may also be highly asymmetric across the regimes in an MS-VECM. If this occurs, then the MS-VECM provides additional insight into the financial and economic dynamics which the linear model cannot provide with its single regime. Moreover, when a structural change occurs, a time-varying process poses a problem for estimation and forecasting in the single regime because there would be a shift in the parameters. This process leads to treating regime shifts not as a singular event but rather as a system governed by an exogenous stochastic process.

Upon examining the estimation results for the short-run adjustments in Table 5 for the MS-VECM, the evidence shows the presence of two regimes and two lags. One can realize two findings from the estimation of this model: all the variables under both regimes have many significant relationships, and the relationships are more significant under the first than the second regime (regime 2). The LR statistic rejects the linear specification in favour of the MS-
VECM using the traditional $p$-value and the Davies (1987) upper bound for the $p$-value. The regime inference statistics (duration, ergodic probabilities and number of observations in each regime) all indicate a significance asymmetry across the regimes. The vector normality test does not reject the normality of the MS-VECM's residuals. Moreover, the vector portmanteau test also does not validate any remaining multivariate autocorrelation, indicating that the selected lag order is sufficient to capture the (cross) autocorrelations.

The smoothed probability estimates for regime 2 are plotted in Fig. 2. The smoothed probability estimates clearly indicate that regime 2 corresponds to recession periods. Indeed, the periods where smoothed probabilities for regime 2 are greater than 0.50 very closely correspond to the recession periods documented by the NBER. Within the sample, the periods February 2001July 2001 and May 2007-July 2009 are the periods corresponding to (recession/crash) regime 2. The NBER recession dates within our sample are the months March 2001-December 2001 (which correspond to the US 2001 dotcom recession) and December 2007-July 2009 (matching the Great Recession). Thus, anecdotally the dates of regime 2 clearly match the NBER recession dates. Moreover, the ratios of variances of regime 2 to regime 1 are 5.93, 1.15, 1.45 and 1.20, respectively, for the IPL, KPL, RIR and OIL equations. Thus, the volatility of regime 2 (recession or turmoil) is significantly higher than the volatility of regime 1 (expansion, tranquility or noncrisis). These findings are consistent with properties of the recession and tranquility regimes.

The results show full significant feedback relationships between industrial production per capita, capital stock per capita and real long-run interest rate under the first regime (regime 1). It is worth noting that VIX, which captures fear and volatility in the stock market, has a significant influence on the real economic activity and the financial variables, except the capital stock per capita under regime 1, but it affects all variables under regime 2 which is the highvolatility regime, underscoring the impact of fear in the stock market on the system. On the other hand, FSI has a significant impact on all real and financial variables under both regimes, except the capital stock per capita under regime 1 and the industrial 
Table 5. Estimation of the MS-VECM

\begin{tabular}{|c|c|c|c|c|}
\hline Variable & $\triangle I P L_{t}$ & $\Delta K L_{t}$ & $\Delta R I R_{t}$ & $\Delta O I L_{t}$ \\
\hline \multicolumn{5}{|c|}{ Low-volatility regime (regime 1) } \\
\hline Constant & $0.00835 * * *(0.00151)$ & $0.00117 * * *(0.00016)$ & $-0.48222 * * *(0.07250)$ & $0.01221(0.01894)$ \\
\hline$\Delta I P L_{t-1}$ & $-0.20327 * * *(0.04736)$ & $-0.03694 * * *(0.00758)$ & $-4.44063 *(2.4790)$ & $2.33426^{* * *}(0.61850)$ \\
\hline$\Delta I P L_{t-2}$ & $0.08949 *(0.05200)$ & $-0.02912 * * *(0.00893)$ & $-7.83905 * * *(2.69350)$ & $1.57498 * *(0.68850)$ \\
\hline$\Delta K L_{t-1}$ & $-2.27095^{* * *}(0.26060)$ & $0.29968 * * *(0.04581)$ & $24.52500 * * *(0.32070)$ & $-1.93698(2.34250)$ \\
\hline$\Delta K L_{t-2}$ & $-0.56518 * *(0.28815)$ & $0.25653 * * *(0.04439)$ & $-8.50301 * * *(0.32010)$ & $6.13614 * * *(1.88450)$ \\
\hline$\Delta R I R_{t-1}$ & $0.00161 * * *(0.00062)$ & $0.00030 * * *(0.00010)$ & $-0.20842 * * *(0.04052)$ & $0.03300 * * *(0.00867)$ \\
\hline$\Delta R I R_{t-2}$ & $-0.00135 * *(0.00058)$ & $-0.00023 * *(0.00011)$ & $-0.18688 * * *(0.03978)$ & $0.01886 * *(0.00826)$ \\
\hline$\Delta O I L_{t-1}$ & $-0.02404 * * *(0.00285)$ & $-0.00102 *(0.00053)$ & $0.16670(0.18975)$ & $0.10618 * * *(0.03896)$ \\
\hline$\Delta O I L_{t-2}$ & $-0.00533 *(0.00321)$ & $0.00030(0.00054)$ & $1.42691 * * *(0.20080)$ & $0.06974(0.04266)$ \\
\hline$V I X_{t-1}$ & $0.00306(0.00200)$ & $0.00058(0.00036)$ & $0.07893(0.13410)$ & $-0.02649(0.02780)$ \\
\hline$V I X_{t-2}$ & $-0.00579 * * *(0.00215)$ & $-0.00007(0.00039)$ & $-0.82232 * * *(0.13895)$ & $-0.04332(0.02992)$ \\
\hline$F S I_{t-1}$ & $0.00330 * * *(0.00089)$ & $0.00024(0.00016)$ & $0.31664 * * *(0.05995)$ & $-0.03601 * * *(0.01263)$ \\
\hline$F S I_{t-2}$ & $-0.00122(0.00078)$ & $-0.00005(0.00014)$ & $-0.03776(0.05195)$ & $-0.08854 * * *(0.01085)$ \\
\hline$E C T 1_{t-1}$ & $-0.02935^{* * *}(0.00973)$ & $-0.00102 * * *(0.00007)$ & $1.07411 * *(0.50940)$ & $-0.15600(0.11780)$ \\
\hline$E C T 2_{t-1}$ & $0.06888 * * *(0.02306)$ & $0.00246^{* * *}(0.00016)$ & $-2.64068 * *(1.21500)$ & $0.36427(0.28040)$ \\
\hline Variance & $0.0000059^{* * *}$ & $0.0000006^{* * *}$ & $0.0033250 * * *$ & $0.0882060 * * *$ \\
\hline \multicolumn{5}{|c|}{ High-volatility regime (regime 2) } \\
\hline Constant & $-0.00288^{* * *}(0.00080)$ & $0.00049 * * *(0.00015)$ & $-0.03274(0.04910)$ & $-0.00367(0.01110)$ \\
\hline$\Delta I P L_{t-1}$ & $-0.39478 * * *(0.05265)$ & $0.01016(0.00870)$ & $-12.22780 * * *(1.76350)$ & $-0.04567(0.71350)$ \\
\hline$\Delta I P L_{t-2}$ & $-0.11667 * *(0.04832)$ & $0.01830 * *(0.00826)$ & $-14.05280 * * *(2.17300)$ & $-0.64818(0.66950)$ \\
\hline$\Delta K L_{t-1}$ & $0.46422 *(0.24385)$ & $0.25535 * * *(0.04431)$ & $-55.46160 * * *(0.09110)$ & $-1.51196(1.67550)$ \\
\hline$\Delta K L_{t-2}$ & $0.63783 * * *(0.23360)$ & $0.23917 * * *(0.04288)$ & $23.05050 * * *(0.13555)$ & $4.14456^{* *}(1.80750)$ \\
\hline$\Delta R I R_{t-1}$ & $0.00283 * * *(0.00068)$ & $-0.00042 * * *(0.00012)$ & $-0.07092(0.04435)$ & $0.00674(0.00972)$ \\
\hline$\Delta R I R_{t-2}$ & $0.00265 * * *(0.00069)$ & $0.00001(0.00012)$ & $-0.04134(0.04341)$ & $-0.00442(0.00926)$ \\
\hline$\Delta O I L_{t-1}$ & $-0.02279 * * *(0.00388)$ & $0.00101(0.00067)$ & $-0.30725(0.25055)$ & $0.01270(0.05305)$ \\
\hline$\Delta \mathrm{OIL}_{t-2}$ & $0.00876 * *(0.00377)$ & $-0.00057(0.00069)$ & $0.55243 * *(0.24280)$ & $-0.15724 * * *(0.05250)$ \\
\hline$V I X_{t-1}$ & $-0.00024(0.00241)$ & $0.00068(0.00044)$ & $0.78792 * * *(0.16215)$ & $-0.20469 * * *(0.03412)$ \\
\hline$V I X_{t-2}$ & $0.00896^{* * *}(0.00231)$ & $0.00163 * * *(0.00041)$ & $0.62905 * * *(0.15340)$ & $-0.00720(0.03232)$ \\
\hline$F S I_{t-1}$ & $-0.00120(0.00215)$ & $-0.00022(0.00038)$ & $-0.76351^{* * *}(0.14200)$ & $0.20594 * * *(0.03055)$ \\
\hline$F S I_{t-2}$ & $-0.00244(0.00201)$ & $-0.00111 * * *(0.00033)$ & $-0.09855(0.12945)$ & $-0.0526^{*}(0.02753)$ \\
\hline$E C T 1_{t-1}$ & $-0.02610^{* * *}(0.00793)$ & $0.00226 * * *(0.00005)$ & $0.21801(0.44830)$ & $-0.15484(0.10420)$ \\
\hline$E C T 2_{t-1}$ & $0.06017 * * *(0.01818)$ & $-0.00498 * * *(0.00014)$ & $-0.53803(1.02400)$ & $0.34800(0.23890)$ \\
\hline Variance & $0.0000352 * * *$ & $0.0000007 * * *$ & $0.0048374 * * *$ & $0.1061200 * * *$ \\
\hline
\end{tabular}

\begin{tabular}{ll}
\hline Transition probabilities \\
\hline$p_{11}$ & 0.97588 \\
$p_{12}$ & 0.02412 \\
$p_{21}$ & 0.08277 \\
$p_{22}$ & 0.91723
\end{tabular}

Regime inference

\begin{tabular}{llll}
\hline & Duration & $n_{i}$ & Ergodic probabilities \\
\hline Regime 1 & 41.46 months & 181.97 & 0.774347 \\
Regime 2 & 12.08 months & 53.03 & 0.225653
\end{tabular}

\begin{tabular}{|c|c|c|c|}
\hline & Linear VECM & $M S-V E C M$ & \\
\hline $\log L$ & 2422.93832 & 2524.43197 & \\
\hline AIC & -20.1101100 & -20.2760168 & \\
\hline \multicolumn{4}{|c|}{ LR linearity test } \\
\hline & LR & $\chi^{2} p$-value & Davies $p$-value \\
\hline & 202.9873 & $<0.01$ & $<0.01$ \\
\hline
\end{tabular}

Vector normality test: $\chi^{2}(8)=14.062$ [0.080]; vector portmanteau test: $\chi^{2}(576)=599.28[0.2431]$

Notes: the table reports estimation results for the MS-VECM given in Equation 4 and linearity tests. The lag order is selected by the BIC as 2 for both linear VEC and MS-VECM. The MS-VECM is estimated using the Bayesian MCMC method where we utilize Gibbs sampling. The MCMC estimates are based on 20000 burn-in and 50000 posterior draws. All reported estimates in the table for the MS-VECM are obtained from the Bayesian estimation. The likelihood ratio (LR) statistic tests the linear VECM under the null against the alternative MS-VECM. The test statistic is computed as the LR test. The LR test is nonstandard since there are unidentified parameters under the null. The $\chi^{2} p$-values (in square brackets) with degrees of freedom equal to the number of restrictions as well as the number of restrictions plus the numbers of parameters unidentified under the null are given. Vector normality test is calculated using the approach proposed in Doornik and Hansen (1994). Regime properties include ergodic probabilities (long-run average probabilities of the Markov process), observations falling in a regime $\left(n_{i}\right)$ based on regime probabilities, and average duration of a regime. The $p$-values of the Davies (1987) test are also given. The models are estimated over the full sample period December 1993-October 2013, with 238 observations (235 after adjusting for lags and differencing). $\Delta$ denotes first differencing. Numbers inside the square brackets are $p$-values. $* * *, * *$ and $*$ represent significance at the $1 \%, 5 \%$ and $10 \%$ levels, respectively. 


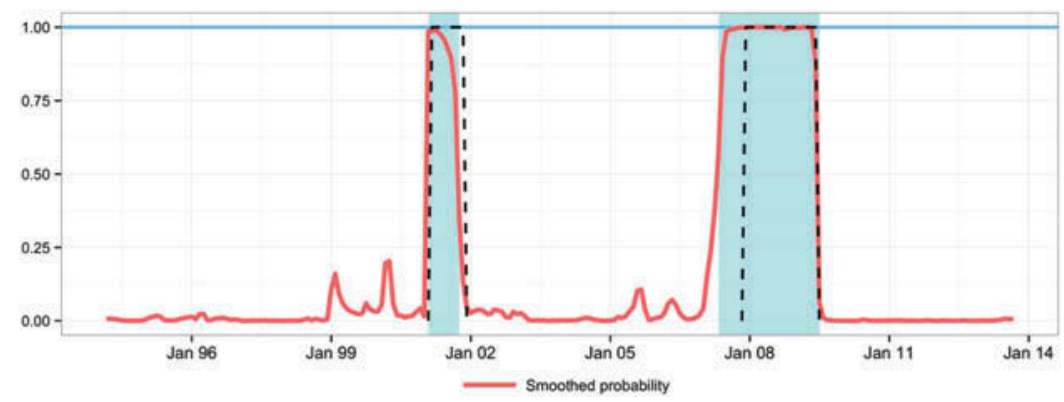

Fig. 2. Estimate of smoothed regime probabilities high volatility or recession regime (regime 2)

Notes: the figure plots the smoothed probability estimates of the high-volatility regime or recession regime (regime 2). The smoothed probabilities correspond to the MS-VECM in Equation 4. The lag order of the estimated MS-VECM is 2 which is selected by the BIC. The MS-VECM is estimated using the Bayesian MCMC method where we utilize the Gibbs sampling. The MCMC estimates are based on 20000 burn-in and 50000 posterior draws. The MCMC method uses the Forward Filter-Backwards Sampling (FFBS) algorithm (multi-move sampling) described in Chib (1998) to sample the regimes. The smoothed probabilities in the figure are the means of the 50000 posterior draws for each time period based on the FFBS algorithm. The shaded regions in the figures correspond to the periods where the smoothed probability of the corresponding regime is the maximum. The dashed black line in the figure corresponds to recessions as documented by the National Bureau of Economic Research (NBER).

production per capita under regime 2 . In general, the impact of FSI, as measured by the sum of the coefficient estimates for lagged variables, tends to be somewhat smaller than that of VIX under regime 1, except its impact on the RIR, and is greater than that of VIX under regime 2.

Finally, the oil price affects all the variables under both regimes, except the capital stock per capita in regime 2 , since oil can wear several hats acting as a factor substitute, a feedstock and a financial variable. The oil price effect, as measured by the sum of the coefficients on the lagged OIL terms, on all variables is negative in regime 1, particularly on IPL, except for the interest rate, which may indicate the presence of a reaction to inflationary impacts of higher oil prices when the economy is in expansion. This effect increases the real long-run interest rate, which implies the oil shock increases inflation expectations. However, the oil impact is mixed in regime 2, being negative on IPL but positive on the KL and RIR.

Finally, the real long-run interest rate has also a significant effect on all variables, having a positive effect on the capital stock per capita, the oil price and the real long-run interest rate, but a negative effect on industrial production per capita in the second period under regime 1 . The positive impact may be related to having an increase in interest rate when the economy is strengthening. In other words, the positive shock in the interest rate may be due to a strong demand shock in a booming economy. The impact in the next regime is mixed and not as significant as regime 1, except its impact on the IPL which may be due to an accommodating economic policy response to recession.

The corrections to the long-run equilibrium are more significant for both cointegrating vectors under the first than regime 2. The speed of adjustment is much higher for the real long-run interest rate than for the real economic and oil price variables under both regimes, although they are not significant in regime 2 . This is not surprising as financial assets move faster than economic and oil variables. Moreover, the oil price which represents commodities that have been financialized adjusts faster than the economic variables under consideration. In regime 1 , the economic variables and the long-run interest rate behave weakly endogenously, while in regime 2 only the economic variables behave weakly endogenously. This implies that oil always works as a weakly exogenous variable, industrial production per capita and capital stock per capita are weakly endogenous in both regimes, but long-run real interest rate is weakly endogenous in regime 1 and weakly exogenous in regime 2. This may be due to more flexibility of the Fed in responding to inflationary pressures 
in the expansion periods but pursuing strict antirecessionary policies during recessions.

The evidence shows that the two regimes have different expected durations. ${ }^{19}$ The expected duration of the high-variance state (regime 2) is only 12.08 months (or 1 year) which is exactly the length of US recessions since WWII, while for the low-variance state (regime 1) it is 41.46 months (or about 3.5 years). Thus, on average the system stays more than 3.43 times as much in the low-volatility (expansion or no crisis) state as in the high-volatility (recession/crash) state, as shown in Fig. 2 for smooth probability. As expected, during the 11 September 2001 New York attack, the 2001-2002 dot-com bubble and the 2007-2009 financial crisis, the system stays most of the time in regime 2 during these periods. However, in the post-Great Recession recovery period and post other crisis periods, the system corrects course and stays in regime 1 (low-volatility regime) all of the time (see Fig. 2). This finding suggests that the system has started to return back to normality for most of the postcrisis periods.

\section{Impulse response analysis under regime-switching}

We perform the RDIR analysis with the $68 \%( \pm 1$ SD) confidence bands for the MS-VECM under two regimes based on 5000 posterior draws with a burn-in of 2000. Figures 3-6 show the results for the impulse response analysis for the MSVECM.

Let us first examine the responses of all variables to a shock from IPL. The positive shock to IPL may be caused by changes is one or both variables that make up this per capita variable. It may be the result of increases in IP or decreases in labour. The responses of IPL to a positive shock of its own are significant as they exponentially drop and then die off in about 2 years. However, the gradual decline is much faster in
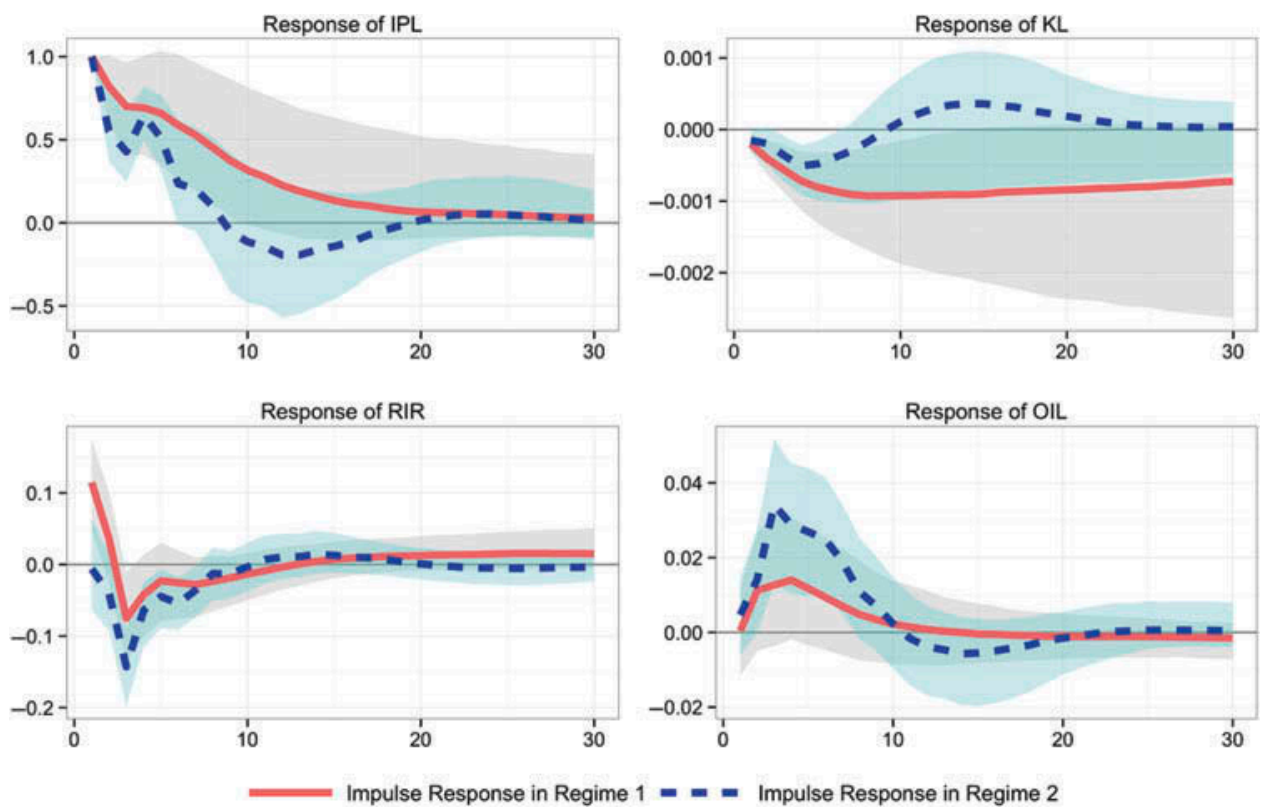

Fig. 3. Impulse responses to a unit shock in real industrial production per capita (IPL)

Notes: the figure gives the impulse responses to a unit shock in per capita industrial production index. The horizontal axis represents the steps in months. The solid line denotes the impulse response in regime 1 , while the dashed line denotes the impulse response in regime 2. The shaded (in grey and light green colours) regions around the impulse response lines represent the $68 \%$ ( $\pm 1 \mathrm{SD}$ ) confidence intervals. All impulses are based on the Cholesky factor orthogonalization. The MSVEC impulse responses and their confidence intervals are computed using the regime-dependent impulse response method suggested by Ehrmann et al. (2003) based on the Gibbs sampling with 50000 posterior draws for each step.

${ }^{19}$ We tested the number of regimes up to 3 . The two-regime model is the preferred one by statistical tests. The results are available upon requests. 

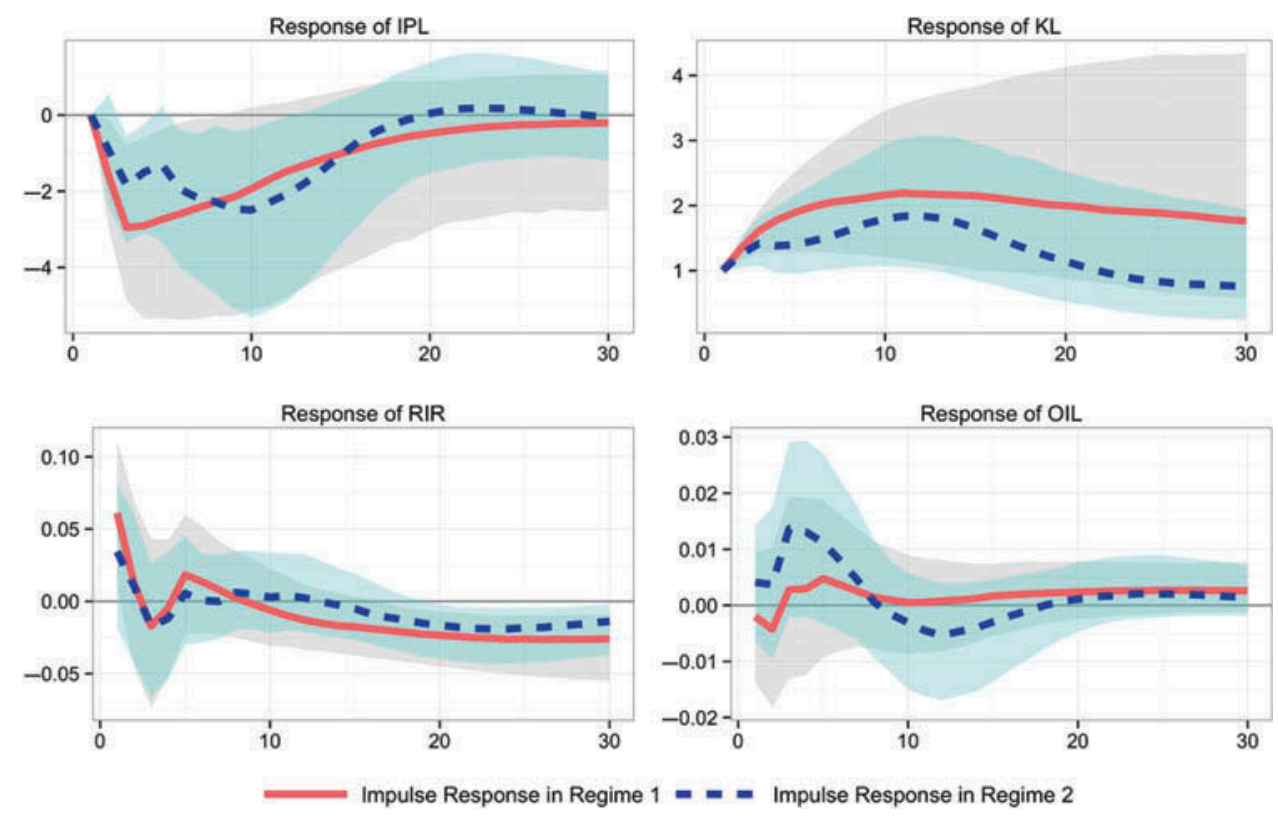

Fig. 4. Impulse responses to a unit shock in per capita capital stock (KL)

Notes: the figure gives the impulse responses to a unit shock in per capita capital stock. The horizontal axis represents the steps in months. The solid line denotes the impulse response in regime 1, while the dashed line denotes the impulse response in regime 2 . The shaded (in grey and light green colours) regions around the impulse response lines represent the $68 \%$ ( $\pm 1 \mathrm{SD})$ confidence intervals. All impulses are based on the Cholesky factor orthogonalization. The MS-VEC impulse responses and their confidence intervals are computed using the regime-dependent impulse response method suggested by Ehrmann et al. (2003) based on the Gibbs sampling with 50000 posterior draws for each step.
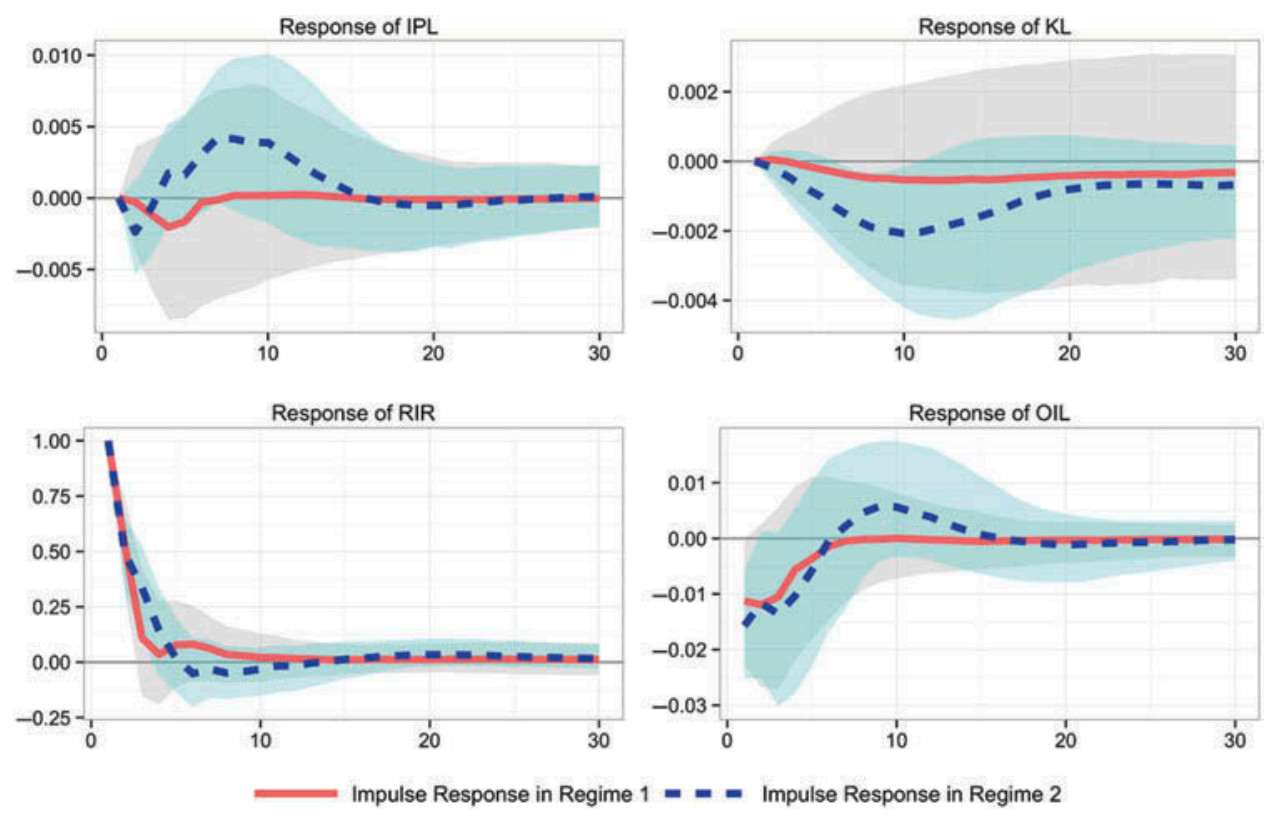

Fig. 5. Impulse responses to a unit shock in real interest rate (RIR)

Notes: the figure gives the impulse responses to a unit shock in real interest rate. The horizontal axis represents the steps in months. The solid line denotes the impulse response in regime 1, while the dashed line denotes the impulse response in regime 2 . The shaded (in grey and light green colours) regions around the impulse response lines represent the $68 \%( \pm 1 \mathrm{SD})$ confidence intervals. All impulses are based on the Cholesky factor orthogonalization. The MS-VEC impulse responses and their confidence intervals are computed using the regime-dependent impulse response method suggested by Ehrmann et al. (2003) based on the Gibbs sampling with 50000 posterior draws for each step. 

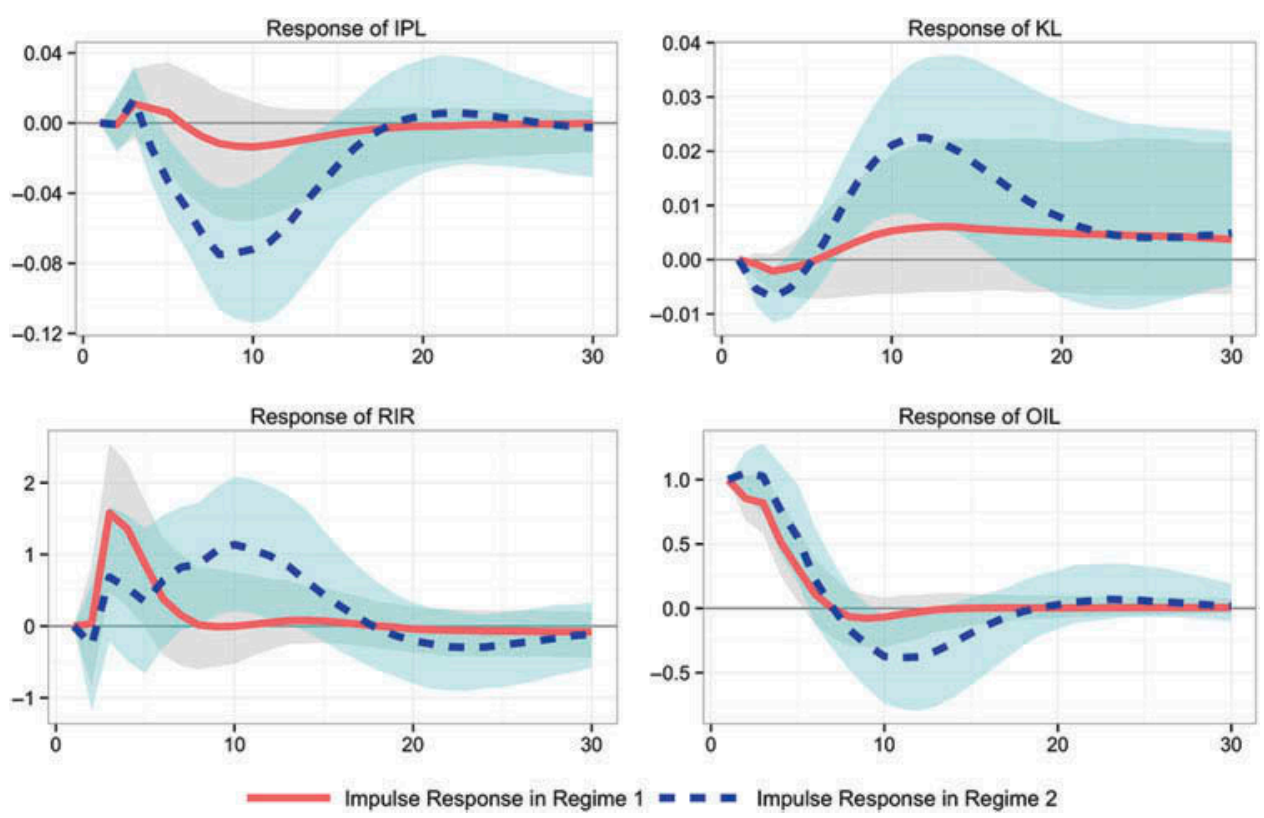

Fig. 6. Impulse responses to a unit shock in oil price (OIL)

Notes: the figure gives the impulse responses to a unit shock in oil price. The horizontal axis represents the steps in months. The solid line denotes the impulse response in regime 1, while the dashed line denotes the impulse response in regime 2. The shaded (in grey and light green colours) regions around the impulse response lines represent the $68 \%( \pm 1 \mathrm{SD})$ confidence intervals. All impulses are based on the Cholesky factor orthogonalization. The MS-VEC impulse responses and their confidence intervals are computed using the regime-dependent impulse response method suggested by Ehrmann et al. (2003) based on the Gibbs sampling with 50000 posterior draws for each step.

the regime 2 (high volatility/recession), even turns negative in the 9th month and stays negative until the 24th month. Interestingly, the shocks on IPL die off in 2 years in both regimes even though the responses are quite different before they die off. The reactions of KL to the positive shock in IPL are to drop initially under both regimes but the KL quickly starts rising after 3 months and becomes positive after 9 months in regime 2. The drop in KL becomes persistent in regime 1, indicating that the output shock for the per capita capital stock is antipersistent in the recession regime. The drop in the per capita capital under both regimes suggests that the per capita output shock work as a productivity shock and as investment decreases industrial production per capita drops. It also implies that the variable that has dropped more likely is IP and not labour. The real long-run interest rate initially goes up before stabilizing under the low-volatility regime and directly goes in the high-volatility regime (regime 2), which collaborates with the declines in IP and the capital stock. The impact on interest rate disappears in 1 year in both regimes. The oil price, which is also a global factor, responds positively under both regimes, which may suggest that a positive output shock in the US drives up the oil demand due to the economic expansion, pushing the oil price up (Fig. 6).

A shock to the per capita capital stock means a shock to the capital stock, labour or both. When it is positive, it means capital stock goes up or labour goes down. The responses of KL to its own shocks are also significant and they gradually go up and then stay steady and persistent as the economy recovers under both regimes. The responses in the low-volatility regime are, however, faster and, in the long run, are about twice the magnitude of the responses in the high-volatility regime. The responses level off in about 12 months under the low-volatility regime and 24 months under the high-volatility regime. The initial impact on RIR is positive but not significant in both regimes; however, the responses eventually become negative and significant under both regimes. Oil also exhibits a quite asymmetric response, with regime 2 having fluctuating 
magnitudes under both regimes, but the responses are insignificant.

When it comes to the responses to the RIR shocks, this variable rises considerably after a positive initial own shock. This leads to a negative initial response from IPL in both regimes, although the responses in the high-volatility regime become positive in 3 months and then dies off in about a year. The responses of KL are also negative but insignificant under both regimes. The oil price initially goes down before it rises and later stabilizes in about 16 months. However, this response is different under the second (high) volatility regime as it turns positive in 6 months and before it eventually moves down and stabilizes. The responses are, however, significant only in the initial 2 months.

The responses of industrial production per capita, capital stock per capita and the long-run real interest rate to an oil price shock are much more asymmetric compared to the other responses. The responses to the oil shocks are more volatile and higher in magnitude in the second (high volatility or recession regime) regime than the first one. Although the responses of industrial production per capita are negative in both regimes, in the high-volatility regime they are much larger and faster, while the responses in regime 1 are small and insignificant. The impulse response of the output per capita to oil price shock resembles a typical oil price shock, which works as a negative supply shock. The response of the capital stock per capita to the oil price shock looks like a mirror image of the response of the industrial production per capita, positive in both regimes but much larger in the recession regime and insignificant in the expansion regime. The positive response of the capital stock per capita is due to the recessionary impact of the oil price shock, which reduces employment and increases the capital per capita given that the aggregate capital stock is fixed in the short run. The interest rate responds positively and significantly to the oil price shock in both regimes, but the response in the low-volatility regime is slower and long-lasting. The responses of industrial production per capita, capital stock per capita and the long-run interest rate to oil price shocks all die off in 2 years in both regimes.
The responses of the oil price to its own shocks exponentially decay towards zero and become insignificant in 6 months, indicating that the oil price shock has a more persistent impact on other variables than itself.

\section{Conclusion}

The major goal of this article is to examine and quantify the linkages between real and financial variables in the United States in an environment that accounts for high volatility in the stock market and high stress in financial markets. This objective has been first examined by employing a linear VECM for the real and financial sides of the economy. This model shows there are some interactions between the variables. However, the linearity test shows that the linear model should be rejected. Therefore, we employ the Markov-switching VECM to examine the same objective using the Bayesian MCMC method. Many more interactions between the real and economic variables have been found in the low- (regime 1) than the high-volatility regime 2 of this model than in the single-regime, linear model.

The corrections to the long-run equilibrium for industrial production per capita and capital stock per capita are significant for both cointegrating vectors under both regimes, but only significant for the long-run interest rate in the low-volatility regime and not significant for the oil price in both regimes, implying that this price is weakly exogenous in both regimes, and the long-run interest rate is only weakly exogenous in the high-volatility regime. The speed of adjustment is much faster for the real longrun interest rate than for the real economic activity and oil price variables. Moreover, the oil price shows higher speed of adjustment to the long-run equilibrium than the real economic variables due to financialization of its market. These two results together demonstrate that the assets that are traded on the financial markets adjust faster than the real economic variables.

We also employ the RDIR function to examine the extent of the responses of shocks to the real and economic variables under the two regimes. We find that the responses and their fluctuations are significantly greater in the high-volatility regime than in the low-volatility regime. FSI, which captures stress in financial markets, has a significant impact on all real 
and financial variables under both regimes, particularly on the real long-run interest rate, except the industrial production per capita in the high-volatility regime. It seems that increases in financial stress go through the long-term interest rate channel first, which in turn affects investment and industrial production per capita. This implication highlights the importance of the financial sector of the economy during stress periods. The financial stress seems to affect the oil market because of increased financialization of this market. The VIX effect is larger than that of FSI in the low-volatility regime and the opposite is true for the high-volatility regime except the impact on the long-run interest rate. High volatility in the stock market as reflected by VIX also affects industrial production per capita, real long-run interest rate and oil price under both regimes. Both FSI and VIX do not affect the capital stock per capita under regime 1, but they have a significant impact in the high-volatility (recession) regime. This implies that VIX, which measures volatility in the expected 30 days, and FSI do not directly affect investment, which usually depends on long-term decisions under the low-volatility regime. However, VIX and FSI affect investment and capital stock in the shorter high-volatility regime. Investors fear high volatility.

When it comes to the WTI price, it is interesting to note that based on the impulse response analysis this price has a negative effect on the IP per worker, and positive effect on the per capita capital stock and the real interest rate. This holds both in the low- and high-volatility regimes and implies that increases in the oil prices depress output and employment. Moreover, given that the capital stock fixed in the short run, the per capita capital stock rises.

Our results have significant policy implications. First, the responses of the real variables to interest and oil price shock are quite asymmetric and the impacts are much larger during the recession periods. The impacts also rise faster during the high-volatility-recession regime. However, complete impacts only level off in 2 years both in the low- and high-volatility regimes. Thus, the impacts of shocks are quite persistent even in the high-volatility regime. Second, there is a significant direct impact of financial variables on the output but the investment impact works through investment. Thus, the impact of the financial risk works through the interest rate rather than directly, impacting the investment decisions. Therefore, policymakers should be ready to accommodate financial shocks by responding with changes in interest rates. Third, the impact of the oil price shock on the per capita capital stock is permanent, working through reducing employment. Thus, the oil shock works as a negative supply shock and calls for policies that restore employment. Fourth, the impact of the financial shocks seems to be more direct on the output and larger than it is thought to be. Policymakers should be aware that financial shocks may have large real impacts as the recent Great Recession proves it to be the case.

\section{Disclosure Statement}

No potential conflict of interest was reported by the authors.

\section{References}

Aboura, S. and van Roye, B. (2013) Financial stress and economic dynamics: an application to France, Kiel Working Papers 1834, Kiel Institute for the World Economy, Kiel.

Ahmed, S., Levin, A. and Wilson, B. A. (2004) Recent U. S. macroeconomic stability: good policies, good practices, or good luck?, The Review of Economics and Statistics, 86, 824-32. doi:10.1162/ 0034653041811662

Alexander, C. and Kaeck, A. (2008) Regime dependent determinants of credit default swap spreads, Journal of Banking \& Finance, 32, 1008-21. doi:10.1016/j.jbankfin.2007.08.002

Andreopoulos, S. (2009) Oil matters: real input prices and U.S. unemployment revisited, The B.E. Journal of Macroeconomics, 9, 1-9. doi:10.2202/19351690.1632

Ardia, D. (2003) Fear trading. Available at http://mpra.ub. uni-muenchen.de/12983/

Bai, J. and Perron, P. (1998) Estimating and testing linear models with multiple structural changes, Econometrica, 66, 47-78. doi:10.2307/2998540

Bai, J. and Perron, P. (2003) Computation and analysis of multiple structural change models, Journal of Applied Econometrics, 18, 1-22. doi:10.1002/ (ISSN)1099-1255

Balcilar, M., Gupta, R. and Miller, S. M. (2015) Regime switching model of US crude oil and stock market prices: 1859 to 2013, Energy Economics, 49, 31727. doi:10.1016/j.eneco.2015.01.026

Bekaert, G., Hoerova, M. and Lo Duca, M. (2012) Risk, uncertainty and monetary policy. Available at SSRN: http://ssrn.com/abstract $=1561171$

Bernanke, B. and Gertler, M. (1999) Monetary policy and asset volatility, Federal Reserve Bank of Kansas City Economic Review, 84, 17-52. Fourth Quarter 1999. 
Bhar, R. and Hamori, S. (2003) Alternative characterization of the volatility in the growth rate of real GDP, Japan and the World Economy, 15, 223-31. doi:10.1016/S0922-1425(02)00012-9

Blanchard, O. and Simon, J. (2001) The long and large decline in U.S. output volatility, Brookings Papers on Economic Activity, 2001, 135-74. doi:10.1353/ eca.2001.0013

Bollerslev, T., Tauchen, G. and Zhou, H. (2009) Expected stock returns and variance risk premia, Review of Financial Studies, 22, 4463-92. doi:10.1093/rfs/ hhp008

Camacho, M. (2005) Markov switching stochastic trends and economic fluctuations, Journal of Economic Dynamics \& Control, 29, 135-58. doi:10.1016/j. jedc.2003.07.002

Camacho, M. (2011) Markov-switching models and the unit root hypothesis in real U.S. GDP, Economics Letters, 112, 161-4. doi:10.1016/j. econlet.2011.03.019

Case, K., Quigley, J. and Shiller, R. (2013) Wealth effects revisited: 1975-2012, NBER Working Paper No. 18667, Cowles Foundation for Research in Economics, Yale University, New Haven, CT.

Çatik, N. and Önder, A. Ö. (2011) Inflationary effects of oil prices in Turkey: a regime-switching approach, Emerging Markets Finance and Trade, 47, 125-40. doi:10.2753/REE1540496X470506

Çevik, E. İ., Korkmaz, T. and Atukeren, E. (2012) Business confidence and stock returns in the USA: a time-varying Markov regime-switching model, Applied Financial Economics, 22, 299-312. doi:10.1080/09603107.2011.610742

Chauvet, M. (1998/1999) Stock market fluctuations and the business cycle, Journal of Economic and Social Measurement, 25, 235-58.

Chen, N.-F., Roll, R. and Ross, S. A. (1986) Economic forces and the stock market, The Journal of Business, 59, 383-403. doi:10.1086/jb.1986.59.issue-3

Chen, S.-S. (2010) Do higher oil prices push the stock market into bear territory?, Energy Economics, 32, 490-5. doi:10.1016/j.eneco.2009.08.018

Cheung, Y.-W. and Ng, L. K. (1996) A causality-in-variance test and its application to financial market prices, Journal of Econometrics, 72, 33-48. doi:10.1016/0304-4076(94)01714-X

Chib, S. (1998) Estimation and comparison of multiple change-point models, Journal of Econometrics, 86, 221-41.

Chow, G. C. and Lin, A. (1971) Best linear unbiased interpolation, distribution and extrapolation of time series by related series, The Review of Economics and Statistics, 53, 372-5. doi:10.2307/1928739

Davies, R. B. (1987) Hypothesis testing when a nuisance parameter is present only under the alternative, Biometrika, 74, 33-43.

Dickey, D. A. and Fuller, W. A. (1979) Distribution of the estimators for autoregressive time series with a unit root, Journal of the American Statistical Association, 74, 427-431.

Diebold, F. X., Lee, J.-H. and Weinbach, G. C. (1994) Regime switching with time-varying transition probabilities, in Nonstationary Time Series Analysis and Cointegration, Hargreaves, C. (Ed), Oxford University Press, Oxford, pp. 283-302.

Dionne, G., Gauthier, G., Hammami, K. et al. (2011) A reduced form model of default spreads with Markovswitching macroeconomic factors, Journal of Banking \& Finance, 35, 1984-2000. doi:10.1016/j. jbankfin.2011.01.001

Doornik, J. A. and Hansen, H. (1994) A practical test for univariate and multivariate normality, Discussion paper, Nuffield College, Oxford.

Durland, J. M. and McCurdy, T. H. (1994) Durationdependent transitions in a Markov model of U.S. GNP growth, Journal of Business and Economic Statistics, 12, 279-88.

Ehrmann, M., Ellison, M. and Valla, N. (2003) Regimedependent impulse response functions in a Markovswitching vector autoregression model, Economics Letters, 78, 295-9. doi:10.1016/S0165-1765(02) 00256-2

Fernandes, M., Medeiros, M. C. and Scharth, M. (2009) Modeling and predicting the CBOE market volatility index. Available at http://Ibspace.qmul.ac.uk/mfer nandes/Papers/Vix.pdf

Fernandez, V. (2014) Commodities and macroeconomic factors: unconditional volatility measures, Emerging Markets Finance and Trade, 50, 87-109.

Figuerola-Ferretti, I. and Paraskevopoulos, I. (2010) Pairing market with credit risk. Available at SSRN: http://ssrn.com/abstract $=1553863$

Filardo, A. J. (1994) Business-cycle phases and their transitional dynamics, Journal of Business and Economic Statistics, 12, 299-308.

Filardo, A. J. and Gordon, S. F. (1998) Business cycle durations, Journal of Econometrics, 85, 99-123. doi:10.1016/S0304-4076(97)00096-1

Forni, M., Hallin, M., Lippi, M. et al. (2003) Do financial variables help forecasting inflation and real activity in the euro area?, Journal of Monetary Economics, 50, 1243-55. doi:10.1016/S0304-3932 (03)00079-5

Francis, N. and Owyang, M. T. (2003) Asymmetric common trends: an application of monetary policy in Markov switching VECM, Working Paper 2003 001B, Federal Reserve Bank of St. Louis, St. Louis, MO.

Gelain, P. and Lansing, K. J. (2013) House prices, expectations and time-varying fundamentals, Working Paper 2013-03, Federal Reserve Bank of San Francisco, San Francisco, CA.

Ghysels, E. (1994) On the periodic structure of the business cycle, Journal of Business and Economic Statistics, 12, 289-98.

Giot, P. (2003) The Asian financial crisis: the start of a regime switch in volatility, Center for Operations 
Research and Econometrics, (CORE) Discussion Papers 2003078, Université catholique de Louvain, Louvain-la-Neuve.

Gogineni, S. (2010) Oil and the stock market: an industry level analysis, The Financial Review, 45, 995-1010. doi:10.1111/fire.2010.45.issue-4

Guerrieri, L. and Iacoviello, M. (2013) Collateral Constraints and Macroeconomic Asymmetries, mimeo, Boston College, Chestnut Hill, MA.

Guidolin, M. and Timmermann, A. (2008) International asset allocation under regime switching, skew, and kurtosis preferences, Review of Financial Studies, 21, 889-935. doi:10.1093/rfs/hhn006

Gupta, R. and Hartley, F. (2013) The role of asset prices in forecasting inflation and output in South Africa, Journal of Emerging Market Finance, 12, 239-91. doi:10.1177/09726527 13512913

Hall, S., Psaradakis, Z. and Sola, M. (1999) Detecting periodically collapsing bubbles: a Markov-switching unit root test, Journal of Applied Econometrics, 14, 143-54. doi:10.1002/(ISSN)1099-1255

Hamilton, J. D. (1989) A new approach to the economic analysis of nonstationary time series and the business cycle, Econometrica, 57, 357-84. doi:10.2307/ 1912559

Hamilton, J. D. (1990) Analysis of time series subject to changes in regime, Journal of Econometrics, 45, 3970. doi:10.1016/0304-4076(90)90093-9

Hamilton, J. D. (1994) Time Series Analysis, Princeton University Press, Princeton, NJ.

Hamilton, J. D. (2003) What is an oil shock?, Journal of Econometrics, 113, 363-98. doi:10.1016/S03044076(02)00207-5

Hamilton, J. D. (2009) Causes and consequences of the oil shock of 2007-08, Brookings Papers on Economic Activity, 2009, 215-61. doi:10.1353/ eca. 0.0047

Hansen, B. E. (2001) The new econometrics of structural change: dating breaks in U.S. labor productivity, The Journal of Economic Perspectives, 15, 117-28. doi:10.1257/jep.15.4.117

International Monetary Fund (IMF). (2000) World Economic Outlook. Asset Prices and the Business Cycle, World Economic and Financial Surveys, IMF, Washington, DC.

Johansen, S. (1988) Statistical analysis of cointegration vectors, Journal of Economic Dynamics and Control, 12, 231-54. doi:10.1016/0165-1889(88)90041-3

Johansen, S. (1991) Estimation and hypothesis testing of cointegration vectors in gaussian vector autoregressive models, Econometrica, 59, 1551-80. doi: $10.2307 / 2938278$

Kilian, L. (2008) Exogenous oil supply shocks: how big are they and how much do they matter for the US economy?, Review of Economics and Statistics, 90, 216-40. doi:10.1162/rest.90.2.216

Kim, C. J. and Nelson, C. R. (1999) Has the U.S. economy become more stable? A Bayesian approach based on a Markov-switching model of the business cycle, Review of Economics and Statistics, 81, 1-10.

Kim, M.-J. and Yoo, J.-S. (1995) New index of coincident indicators: A multivariate Markov switching factor model approach, Journal of Monetary Economics, 36, 607-30. doi:10.1016/0304-3932(95)01229-X

Krishnamurthy, V. and Rydén, T. (1998) Consistent estimation of linear and non-linear autoregressive models with Markov regime, Journal of Time Series Analysis, 19, 291-307. doi:10.1111/14679892.00093

Krolzig, H. M. (1997) Markov-Switching Vector Autoregressions, Modeling, Statistical Inference and Application to Business Cycle Analysis, Springer, Berlin.

Krolzig, H. M. (1999) Statistical Analysis of Cointegrated VAR Processes with Markovian Regime Shifts, University of Oxford, Oxford.

Krolzig, H. M. (2006) Impulse Response Analysis in Markov Switching Vector Autoregressive Models, Economics Department, University of Kent, Keynes College, Canterbury.

Krolzig, H.-M., Marcellino, M. and Mizon, G. (2002) A Markov-switching vector equilibrium correction model of the UK labour market, Empirical Economics, 27, 233-54. doi:10.1007/ s001810100117

Lin, C.-C., Fang, C.-R. and Cheng, H.-P. (2014) The impact of oil price shocks on the returns in China's stock market, Emerging Markets Finance and Trade, 50, 193-205.

Litterman, R. B. (1983) A random walk, Markov model for the distribution of time series, Journal of Business and Economic Statistics, 1, 169-73.

Liu, T. (2013) Essay on credit and market risk measures in a regime-changing environment, essay 1: interrelationships among financial risks with economic activity and oil in a regime-changing environment, Ph.D. dissertation, Drexel University, Philadelphia, PA.

Liu, Z., Wang, P. and Zha, T. (2013) Land-price dynamics and macroeconomic fluctuations, Econometrica, 81, 1147-84. doi:10.3982/ECTA8994

Mian, A. R., Rao, K. and Sufi, A. (2013) Household balance sheets, consumption, and the economic slump, Chicago Booth Research Paper No. 13-42, Fama-Miller Working Paper. Available at http://ssrn. com/abstract $=1961211$ (accessed 14 September 2015).

McConnell, M. M. and Pérez-Quirós, G. (2000) Output fluctuations in the United States: what has changed since the early 1980's, American Economic Review, 90, 1464-76.

Mills, T. C. and Wang, P. (2003) Have output growth rates stabilised? Evidence from the g-7 economies, Scottish Journal of Political Economy, 50, 232-46. doi:10.1111/sjpe.2003.50.issue-3

Moore, G. H. (1983) Security markets and business cycles, in Business Cycles, Inflation, and Forecasting, 2nd edn, Moore, G. H. (Ed), NBER Book Series Studies 
in Business Cycles, NBER, Cambridge, MA, pp. 139-60.

Ng, S. and Perron, P. (2001) Lag length selection and the construction of unit root tests with good size and power, Econometrica, 69, 1519-54.

Ni, S., Sun, D. and Sun, X. (2007) Intrinsic Bayesian estimation of vector autoregression impulse responses, Journal of Business \& Economic Statistics, 25, 16376. doi:10.1198/073500106000000378

Nikkinen, J., Saleem, K., Martikainen, M. et al. (2014) Oil risk and asset returns: evidence from emerging markets in the Middle East, Emerging Markets Finance and Trade, 50, 169-89. doi:10.2753/REE1540-496X5003S310

Perron, P. (2006) Dealing with structural breaks, Palgrave Handbook of Econometrics, 1, 278-352.

Phillips, P. C. B. and Perron, P. (1988) Testing for a unit root in time series regression, Biometrika, 75, 33546. doi:10.1093/biomet/75.2.335

Psaradakis, Z., Sola, M. and Spagnolo, F. (2004) On Markov error-correction models, with an application to stock prices and dividends, Journal of Applied Econometrics, 19, 69-88. doi:10.1002/ (ISSN)1099-1255

Saikkonen, P. (1992) Estimation and testing of cointegrated systems by an autoregressive approximation, Econometric Theory, 8, 1-27. doi:10.1017/ S0266466600010720

Saikkonen, P. and Lütkepohl, H. (2000) Testing for the cointegrating rank of a VAR process with structural shifts, Journal of Business \& Economic Statistics, 18, 451-64.

Saikkonen, P. and Luukkonen, R. (1997) Testing cointegration in infinite order vector autoregressive processes, Journal of Econometrics, 81, 93-126. doi:10.1016/S0304-4076(97)00036-5

Savit, R. (1988) When random is not random: an introduction to chaos in market prices, The Journal of Futures Markets, 8, 271-90. doi:10.1002/(ISSN) 1096-9934

Semmler, W. and Chen, P. (2014) Financial stress, regime switching and macrodynamics: theory and empirics for the US, the EU and Non-EU countries, Economic Perspectives Challenging Financialization, Inequality and Crises. Available at http:/www.eco nomics-ejournal.org/special-areas/special-issues/ economic-perspectives-challenging-financializationinequality-and-crises (accessed 14 September 2015).

Siegel, J. J. (1991) The Behavior of Stock Returns around N.B.E.R. Turning Points: An Overview, Rodney L. White Center for Financial Research, Philadelphia, PA.

Stock, J. H. and Watson, M. W. (2003) Has the business cycle changed? Evidence and explanations, in Proceedings of Symposium on Monetary Policy and Uncertainty: Adapting to a Changing Economy, Federal Reserve Bank of Kansas City, Kansas City, MI, pp. 9-56.

Summers, P. M. (2005) What caused the great moderation? Some cross-country evidence, Economic Review (Third Quarter), 2005, 5-32.

Zhou, X. and Carroll, C. D. (2012) Dynamics of wealth and consumption: new and improved measures for U.S. states, The B.E. Journal of Macroeconomics, 12, 1-44. doi:10.1515/19351690.2403 